\title{
ANÁLISES DO PADRÃO DE RESPOSTA DA FREQÜÊNCIA \\ CARDÍACA PELOS MÉTODOS DE SÉRIES TEMPORAIS E SEMIPARAMÉTRICO E DE SUA VARIABILIDADE NA \\ DETERMINAÇÃO DO LIMIAR DE ANAEROBIOSE
}

\section{Lilian Cristine de Andrade Teixeira}

Dissertação apresentada ao Programa de PósGraduação Interunidades Bioengenharia Escola de Engenharia de São Carlos / Faculdade de Medicina de Ribeirão Preto / Instituto de Química de São Carlos da Universidade de São Paulo, para obtenção do título de Mestre em Bioengenharia.

ORIENTADORA: Profa. Dra. Ester da Silva

São Carlos 
Investigação conduzida no Laboratório de Fisioterapia Cardiovascular - Núcleo de Pesquisa em Exercício Físico do Departamento de Fisioterapia da Universidade Federal de São Carlos, com apoio financeiro das agências CNPq, CAPES e FAPESP. 


\title{
DEDICATÓRIA
}

\author{
AOS MEUS AVÓS \\ ALFREDO PIRES DE ANDRADE E ISOLINA VAQUERO GOMES GODOI \\ HORÁCIO TEIXEIRA E ROSA MANTELO TEIXEIRA
}

OS QUAIS GERARAM AS PESSOAS MAIS MARAVILHOSAS QUE MINHA VIDA PODE CONHECER:

ANTONIO GERALDO TEIXEIRA

MARLENE ARLETE PIRES DE ANDRADE TEIXEIRA 


\section{AGRADECIMENTOS ESPECIAIS}

À DEUS Por dar-me e salvar-me a vida nesses 29 anos de minha existência. Por ter confiado a mim a missão de mostrar meu valor e minha humildade a todos que um dia pude e poderei encontrar!

Aos meus Pais, por estarem presentes até em pensamentos em todos os momentos da vida de seus filhos. Vocês são a minha força aqui na Terra!

À todos meus Familiares, espalhados por todo este país e aos que estão em outro continente, por sempre, em toda minha vida, confiarem em meu potencial, conhecerem o meu trabalho, estando sempre bem perto dando sua força!

Aos meus irmãos Cláudia e Geraldo por participarem intensamente de todos os momentos de minha vida principalmente desses 3 anos de dedicação ao mestrado, ajudando-me nas análises, correções, traduções e muitas outras coisas que eles mesmos saberão.

Ao Marcos pelo apoio, amizade, amor, companheirismo e pelas muitas vezes que me abraçou acreditando que eu chegaria ao fim!!!

Às minhas amigas Andréa, Luciana, Karina, Albaiza e D. Lourdes, vocês têm uma força incrível! Sem vocês tudo teria sido mais difícil.

Ao Mário (DEMA - UFSCar), há pessoas na vida da gente que são colocadas pelas mãos de Deus!

Aos amigos do Laboratório de Fisioterapia Cardiovascular e NUPEF em especial: Eduardo, Liliana, Maria Antonia, Robison, Fernanda, Cristiano, Ana Paula, Valéria, Fabrício, Daniel, Luciana Novais, Michele, Ricardo, Zé Luis, Marcos Leandro, Anielle, Daniela, Pozzi e Lucas. Cada um sabe da enorme importância que teve para 
a realização e conclusão deste trabalho! Somos uma equipe! Esta dissertação é de vocês! Que nós possamos ter demonstrado a nossa garra,o nosso espírito de solidariedade, a nossa amizade, nossa seriedade e a nossa credibilidade em tudo que fizemos e temos a fazer. Mãos à obra porque nossa vida profissional está só começando! Vocês são Grandes Profissionais!

Aos voluntários que participaram deste investigação pela disponibilidade e dedicação nos experimentos.

Ao Departamento Interunidades Bioengenharia (EESC, IFSC, FMRP) - Universidade de São Paulo, em nome do Prof. Dr. José Carlos Pereira, por sua discrição, seriedade, atenção, respeito ao nosso trabalho aceitando-me como aluna do Curso de Mestrado da Bioengenharia.

À Profa. Dra. Ester da Silva, por primeiramente me receber no Laboratório de Fisioterapia Cardiovascular da UFSCar e acreditar em meu trabalho enquanto Fisioterapeuta. Pela orientação, pela amizade, pela paciência, por em grande parte ser responsável por meus conhecimentos na área de Fisioterapia Cardiovascular e Cardiologia, o que veio a me enriquecer em muito e ser reconhecida por meus pacientes e por ser a mola propulsora de minha vida acadêmica, mostrando-me que ser acadêmico não é apenas triar voluntários, avaliá-los conforme a metodologia empregue, participar intensamente dos experimentos, passar meses analisando dados e finalmente sentar ao computador e redigir as partes finais do meu trabalho. Pude com ela, aprender o quanto é imprescindível ajudar e receber o auxílio de muitos, que é preciso deixar de lado a solidariedade (temporariamente) e ser sim um pouco mais solidária as minhas coisas para assim contribuir com crescimento de outros que vierem a precisar de mim. 
À Profa. Dra. Aparecida Maria Catai, por primeiramente me receber no Laboratório de Fisioterapia Cardiovascular da UFSCar e acreditar em meu trabalho enquanto Fisioterapeuta, pela amizade, por estar sempre presente, ajudando, corrigindo, dando sugestões e por sempre dar uma grande força.

Ao Lucien de Oliveira, pela amizade, pelos incontáveis auxílios na parte computacional, formatação de texto, gráficos, tabelas e por acreditar em meu potencial.

À Vera Regina Fernandes da Silva Marães, pela amizade, por ter contribuído desde o início com dados coletados de alguns voluntários, pela sua orientação em parte deste trabalho, pelo auxilio na qualificação e principalmente na redação e digitação final deste trabalho. Verinha, muitíssimo obrigada, sem você nada disso seria possível!

À Dra Silvana M. L. Andrade, ajudando-me a recuperar e superar obstáculos para que eu pudesse chegar ao fim desse trabalho. 


\section{AGRADECIMENTOS}

Aos cardiologistas Dr. Mário R. R. Verzola e Dr. Carlos A. Mega, por contribuírem na avaliação clínica cardiovascular dos voluntários que participaram deste trabalho.

Aos professores do Depto. de Estatística da UFSCar, Prof. Dr. Luis Aparecido Milan, Prof. Dr. Francisco Rojas e Prof. Dr. Jorge Oishi, pelas análises estatísticas e orientações.

A Profa. Simone Teixeira Cassitas, pelas correções do texto, pela atenção, amizade, pelo carinho que tem por mim.

Aos professores do Departamento Interunidades Bioengenharia (EESC, IFSC, FMRP) - Universidade de São Paulo, que contribuíram para o enriquecimento de meus conhecimentos científicos.

A Janete, secretária da Bioengenharia- EESC- USP- São Carlos, pela colaboração, amizade e paciência.

Aos amigos e pacientes do Laboratório de Fisioterapia Cardiovascular e do NUPEF do DFisio/UFSCar, vocês são o que levo de mais importante de toda a minha permanência em São Carlos. 
LISTA DE FIGURAS

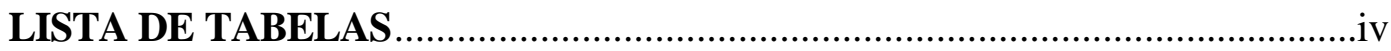

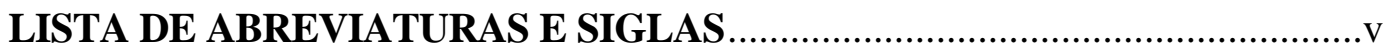

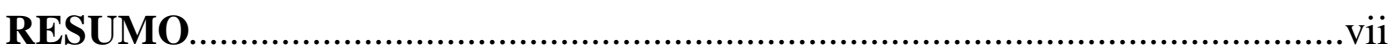

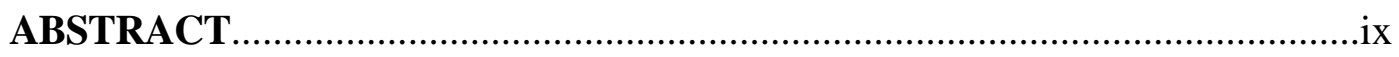

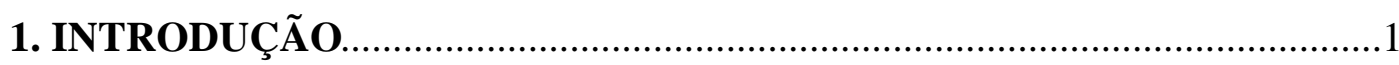

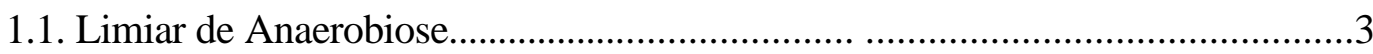

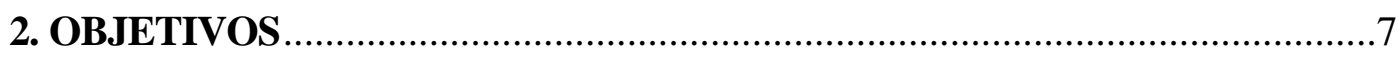

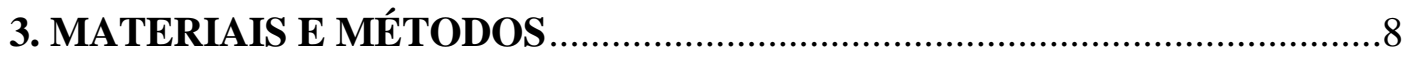

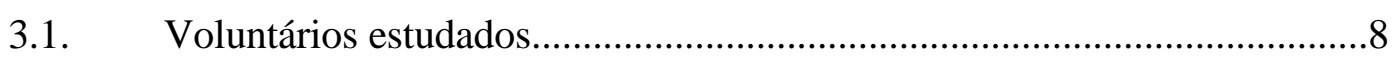

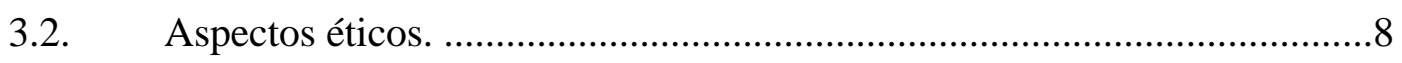

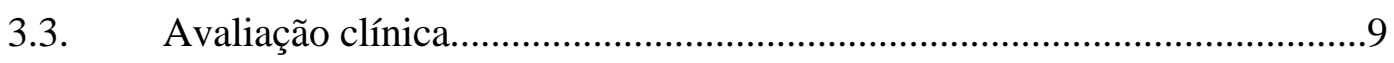

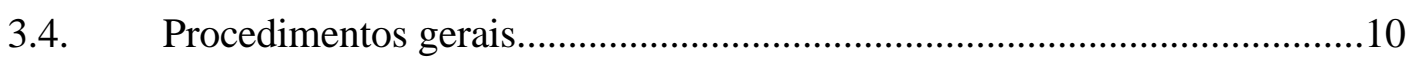

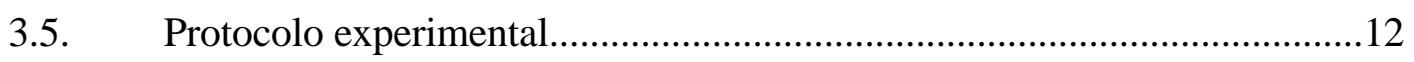

3.5.1. Teste de exercício físico dinâmico descontínuo do tipo degrau (TEFDD-D) com potências progressivas.................................................12

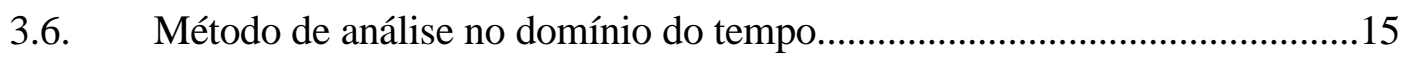

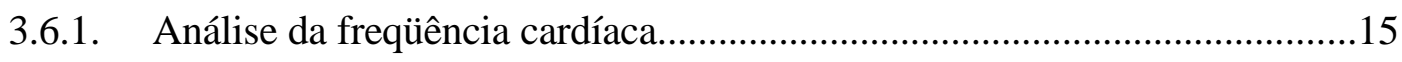

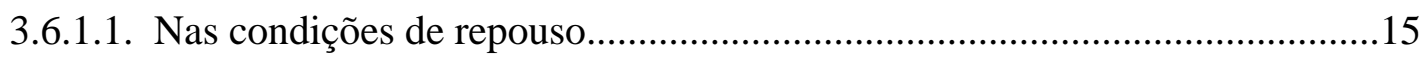

3.6.1.2. Nas condições de exercício físico dinâmico descontínuo...............................15

3.6.2. Análise da variabilidade da freqüência cardíaca.........................................16

3.7. Análise da resposta da frequiência cardíaca na determinação do limiar

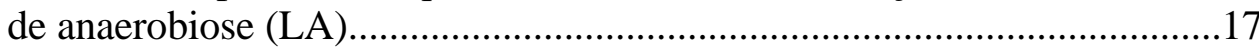

3.7.1. Ajuste do modelo matemático e estatístico semiparamétrico ao conjunto de dados de frequiência cardíaca obtidos durante o TEFDDD. 
3.7.2. Ajuste dos modelos autorregressivos integrados médias móveis (ARIMA)

3.8. Metodologia estatística.

4. RESULTADOS

4.1. Voluntários estudados

4.2. Análise descritiva e no domínio do tempo da freqüência cardíaca em repouso.

4.2.1. Freqüência cardíaca em repouso.

4.2.2. Variabilidade da frequiência cardíaca em repouso.

4.3. Frequiência cardíaca durante o teste de exercício físico dinâmico em degraus descontínuos.

4.3.1. Variação da frequiência cardíaca e do tempo no início do exercício físico.

4.4. Análise da variabilidade da frequiência cardíaca durante o teste de exercício físico dinâmico em degraus descontínuos.

4.5. Nível de potência em Watts atingida no teste de avaliação da capacidade funcional e no nível do limiar de anaerobiose

4.5.1. Percentual de potência ao nível do limiar de anaerobiose determinado pelas análises dos modelos semiparamétrico e do modelo ARIMA em relação à potência pico atingida no teste de exercício físico dinâmico contínuo.

4.5.2. Freqüência cardíaca pico atingida durante o teste de avaliação da capacidade funcional e no nível do limiar de anaerobiose.

4.5.3. Percentual da freqüência cardíaca ao nível do limiar de anaerobiose determinado pelas análises dos modelos SMP e ARIMA em relação à potência pico atingida no teste de exercício físico dinâmico contínuo.

4.5.4. Análise da variabilidade da frequiência cardíaca durante o TEFDD-D nos níveis de potências em que foi determinado o limiar de anaerobiose.

4.6. Análises de correlação.

4.6.1. Análise de correlação entre as potências atingidas no momento do limiar de anaerobiose determinado pelos modelos semiparamétrico 
e ARIMA durante o TEFDD-D.

4.6.2. Análise de correlação entre valores de freqüência cardíaca no nível de potência do limiar de anaerobiose, durante o TEFDD-D.

4.6.3. Análise de correlação entre valores do índice de variabilidade da frequiência cardíaca (RMSSD) no nível de potência do limiar de anaerobiose, durante o TEFDD-D.

5. DISCUSSÃO. . .36

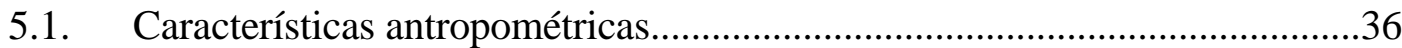

5.2. Análise da resposta da frequiência cardíaca e de sua variabilidade...................37

5.2.1. Na condição de repouso nas posições supina e sentada.................................37

5.3. Padrão de resposta da frequiência cardíaca durante o esforço físico.................39

5.3.1. Análise descritiva e no domínio do tempo....................................................39

5.4. Análise da resposta da freqüência cardíaca e de sua variabilidade durante o exercício físico dinâmico

5.5. Aplicação de modelos matemáticos e estatísticos na análise do padrão de resposta da freqüência cardíaca em exercício físico na determinação do limiar de anaerobiose.

5.5.1. Modelos autorregressivos-integrados-médias móveis (ARIMA) na detecção do limiar de anaerobiose.

5.5.2. Modelo matemático e estatístico semiparamétrico na detecção do limiar de anaerobiose.

5.5.3. Percentual de frequiência cardíaca e de potência de esforço físico em relação aos valores pico: úteis para prescrever exercício físico

6. CONCLUSÕES .48

7. REFERÊNCIAS BIBLIOGRÁFICAS .49

APÊNDICE 1. .58

APÊNDICE 2 


\section{LISTA DE ABREVIATURAS E SIGLAS}

ARIMA - Modelos autorregressivos-integrados-médias móveis

ATP - Adenosina Trifosfato

$\mathrm{CO}_{2}$ - Dióxido de carbono

ECG - Eletrocardiograma

FC - Freqüência cardíaca

IMC - Índice de massa corpórea

IRR - Intervalos R-R

LA - Limiar de anaerobiose

MC5 - sistema de derivação para eletrocardiograma de esforço (eletrodo indiferente no manúbrio esternal, explorador na posição V5 (5- espaço intercostal na linha axilar anterior esquerda) e o terra em V5 a direita.

ms - milissegundos

$\mathrm{O}_{2}-$ Oxigênio

PA - Pressão arterial

PAD - Pressão arterial diastólica

PAS - Pressão arterial sistólica

RMSSD - raiz quadrada da somatória do quadrado das diferenças entre os IRR sucessivos no registro do ECG divididos pelo número de IRR menos um.

rs - coeficiente de correlação de Spearman

SMP - Semiparamétrico

TE - Teste ergométrico 
TEFDC-D - Teste de esforço físico dinâmico contínuo do tipo degrau

TEFDD-D - Teste de esforço físico dinâmico descontínuos do tipo degraus.

URA - Umidade relativa do ar

$\dot{\mathrm{V}} \mathrm{E}$ - Ventilação pulmonar

$\dot{\mathrm{V}} \mathrm{CO}_{2}-$ Produção de dióxido de carbono

VFC - Variabilidade da freqüência cardíaca

$\dot{\mathrm{V}} \mathrm{O}_{2}$ - Consumo de oxigênio

Vे $\mathrm{O}_{2}$ máx - Consumo máximo de oxigênio 


\section{LISTA DE FIGURAS}

FIGURA 1. Representação esquemática do teste de exercício físico dinâmico descontínuo do tipo degrau (TEFDD-D), com potências progressivas de incrementos de 10 Watts (W), duração de 6 minutos e com períodos variáveis de repouso, interpostos entre níveis de exercício físico.

FIGURA 2. Ilustração da tela do computador durante a aquisição do ECG e da frequiência cardíaca (FC), batimento a batimento, em tempo real, durante o repouso na posição sentada, de um dos voluntários estudados (FMM).

FIGURA 3. Ilustração da tela do computador do programa "Analisador Gráfico de IRR, FC e ECG" contendo informações do protocolo utilizado, planilha de dados absolutos de iRR e de FC batimento a batimento, gráficos das respostas de FC em exercício físico dinâmico.

FIGURA 4. Ilustração de um gráfico do conjunto de dados de FC e o relatório contendo os dados da série ajustada pelo modelo semiparamétrico, na potência de $85 \mathrm{~W}$, considerado como o nível do LA de um dos voluntários estudados (JRM).

FIGURA 5. Análise dos valores absolutos de freqüência cardíaca, em batimentos por minuto, durante a condição de repouso na posição sentado, de um dos voluntários estudados quanto à distribuição dos dados. Em (A) estão representados a curva de Gauss e o histograma do número de observações e em (B) estão representados os valores observados em relação aos valores esperados.

FIGURA 6. Freqüência cardíaca, obtida batimento a batimento, em tempo real, em repouso nas posições supina e sentada, durante 900s, antes da execução dos testes de exercício físico dinâmico descontínuo do tipo degrau (TEFDD-D) de um dos voluntários estudados (FMM)

FIGURA 7. Frequiência cardíaca média, em batimentos por minuto (bpm), observados durante um período de $900 \mathrm{~s}$ de repouso, nas posições supina e sentada $(\mathrm{N}=12)$. Nível de significância $\alpha=0,05$ 
FIGURA 8. RMSSD dos intervalos R-R em milissegundos (ms), observados durante um período de $900 \mathrm{~s}$, em repouso nas posições supina e sentada dos voluntários estudados $(\mathrm{N}=12)$. Nível de significância $\alpha=0,05$

FIGURA 9. Resposta da freqüência cardíaca captada batimento a batimento, em tempo real, em repouso (60 s), durante $420 \mathrm{~s}$ do teste de exercício físico dinâmico descontínuo, com potências progressivas de $25,35,45,55$ e $65 \mathrm{~W}$ e em recuperação (60 s), realizadas pelo voluntário $\mathrm{CRB}$.

FIGURA 10. Em A, tempo em segundos (s) de elevação da FC nas potências de 25, 35, 45, 55 e 65 Watts (W) durante os TEFDD-D e em B, variação da frequiência cardíaca, em batimentos por minuto (bpm) $(\mathrm{N}=12)$. Nível de significância $\alpha=0,05$.

FIGURA 11. Valores dos índices RMSSD a partir dos intervalos R-R em milissegundos (ms), na condição de repouso sentado e nas potências de 25, 35, 45, 55 e 65 Watts (W), no intervalo de 120 a 420s, durante o TEFDD-D. Nível de significância $\alpha=0,05$. $(\mathrm{N}=12)$.

FIGURA 12. Relação entre os valores de potência pico atingidas durante o TEFDC-D e as potências pico atingidas pelas análises dos modelos semiparamétrico e ARIMA durante os TEFDD-D $(\mathrm{N}=12)$. Nível de significância $\alpha=0,05$.

FIGURA 13. Dados percentuais (\%) da potência de exercício físico no limiar de anaerobiose (LA) pelas metodologias semiparamétrica (SP) e ARIMA em relação `a potência pico atingida durante o teste de exercício físico dinâmico contínuo $(\mathrm{N}=12)$. Nível de significância $\alpha=0,05$. .

FIGURA 14. Relação entre os valores de FC pico atingidas pelas metodologias semiparamétrica (SP) e ARIMA durante os TEFDD-D ( $=12)$. Nível de significância $\alpha=0,05$.

FIGURA 15. Dados percentuais (\%) de freqüência cardíaca em batimentos por minuto (bpm) obtidos no nível do LA, determinado pelas metodologias ARIMA e semiparamétrica (SMP) em relação `a potência pico atingida durante o teste de exercício físico dinâmico contínuo $(\mathrm{N}=12)$. Nível de significância $\alpha=0,05$ 
FIGURA 16. Valores de RMSSD dos intervalos RR em milissegundos (ms) durante o TEFDD-D na potência de 55 Watts (W) e nos níveis de potências em que foi determinado o LA pelas metodologias: ARIMA e semiparamétrica (SMP) $(\mathrm{N}=12)$. Nível de significância $\alpha=0,05$.

FIGURA 17. Associação entre os valores de potência em Watts (W) pelos modelos SMP e ARIMA (N=12). Nível de significância $\alpha=0,05 \ldots . .33$

FIGURA 18. Associação entre os valores de frequiência cardíaca pico em batimentos por minuto, durante o TEFDD-D, atingidas no nível de potência em que foi determinado o LA pelos modelos SMP e ARIMA (N=12). Nível de significância $\alpha=0,05$ .34

FIGURA 19. Associação entre os valores dos índices RMSSD dos intervalos R-R em milissegundos (ms), durante o TEFDD-D, no nível de potência em que ocorreu o LA, pelos dois modelos SMP e ARIMA ( $\mathrm{N}=12)$. Nível de significância $\alpha=0,05$ 


\section{LISTA DE TABELAS}

TABELA 1. Idade, características antropométricas (peso, altura) e índice de massa corporal (IMC) em $\mathrm{Kg} / \mathrm{m}^{2}$ observados nos voluntários estudados $(\mathrm{N}=12)$

TABELA 2. Dados de pressão arterial sistólica (PAS) e diastólica (PAD) em milímetros de mercúrio $(\mathrm{mmHg})$, de frequiência cardíaca (FC) em batimentos por minuto (bpm), em repouso, tipo de atividade física e horas semanais realizadas pelos voluntários $(\mathrm{N}=12)$.

TABELA 3. Dados de pressão arterial sistólica (PAS) e diastólica (PAD) em milímetros de mercúrio $(\mathrm{mmHg})$, de frequiência cardíaca (FC) em batimentos por minuto (bpm) e potência pico em Watts (W) durante TEFDC-D, realizados pelos voluntários $(\mathrm{N}=12)$.

TABELA 4. Dados da umidade relativa do ar (\%) e da temperatura em graus Celsius $\left({ }^{\circ} \mathrm{C}\right)$ da sala de experimento mantidas nos dias da realização dos TEFDD-D $(\mathrm{N}=12)$.

TABELA 5. Valores do índice RMSSD dos intervalos RR em milissegundo (ms) calculados no período de 900 segundos nas condições de repouso supino e sentada dos voluntários $(\mathrm{N}=12)$.

TABELA 6. Valores dos índices de RMSSD dos intervalos R-R em milissegundos $(\mathrm{ms})$ calculados para o período de $1^{\mathrm{o}}$ ao $4^{\mathrm{O}}$ minuto, do teste de esforço físico dinâmico em degraus descontínuos para as potências de $25 \mathrm{~W}, 35 \mathrm{~W}, 45 \mathrm{~W}, 55 \mathrm{~W}$ e $65 \mathrm{~W}(\mathrm{~N}=12)$.

TABELA 7. Resultados dos ajustes dos modelos autorregressivos integrados médias móveis (ARIMA) e semiparamétrico ao conjunto de dados de freqüência cardíaca em todas as potências realizadas pelos voluntários $(\mathrm{N}=12)$.

TABELA 8. Valor do índice RMSSD dos intervalos RR calculados para o período do $1^{\circ}$ ao $4^{\circ}$ minuto, do teste de esforço físico dinâmico em degraus descontínuos, nas potências em que ocorreu o limiar de anaerobiose determinado pelas metodologias ARIMA (ajustes dos modelos autorregressivos integrados médias móveis) e SP (semiparamétrico) $(\mathrm{N}=12)$ 


\section{RESUMO}

TEIXEIRA, L.C.A. Análise do padrão de resposta da freqüência cardíaca pelos métodos de séries temporais e semiparamétrico e de sua variabilidade na determinação do limiar de anaerobiose. São Carlos 2003, 69p. Dissertação (mestrado) Escola de Engenharia de São Carlos / Faculdade de Medicina de Ribeirão Preto / Instituto de Química de São Carlos, Universidade de São Paulo.

O presente trabalho tem como objetivos avaliar a resposta da frequiência cardíaca (FC) e de sua variabilidade nas condições de repouso e em exercício físico dinâmico; determinar o limiar de anaerobiose a partir da análise das respostas de FC durante o exercício físico pelos modelos matemáticos e estatísticos autorregressivos-integradosmédias móveis (ARIMA) e semiparamétrico (SMP) e pelos índices de variabilidade da freqüência cardíaca (VFC); comparar o grau de correlação entre as três metodologias de análise na detecção de alterações no padrão de resposta da FC como indicador do limiar de anaerobiose (LA). Foram estudados doze voluntários com idade em mediana de 42 anos, considerados ativos e saudáveis, a partir dos resultados da avaliação clínica, cardiovascular e do eletrocardiograma (ECG) em repouso e durante teste de esforço físico dinâmico contínuo do tipo degrau (TEFDC-D). O protocolo experimental consistiu de teste de esforço físico dinâmico descontínuo do tipo degrau (TEFDD-D), com potências progressivas de 10 em 10 watts (W) sendo que a potência inicial foi de $25 \mathrm{~W}$. Os intervalos RR (IRR) e a FC, captados a partir dos registros do ECG em tempo real, batimento a batimento, foram obtidos utilizando-se um programa de processamento de sinais. Os dados foram captados na condição de repouso por um período de $900 \mathrm{~s}$ na posição supina, $900 \mathrm{~s}$ na posição sentada e sentado no cicloergômetro durante $60 \mathrm{~s}$ em repouso, 360s em exercício e 60s em recuperação. Foram calculadas: as médias da FC; os índices de RMSSD dos IRR de repouso e em exercício; tempo de variação da $\mathrm{FC}\left(\mathrm{t} / \Delta \mathrm{FC} \mathrm{t}_{1}-\mathrm{t}_{0}\right)$ em segundos onde $\mathrm{t}_{1}$ eqüivale ao instante em que ocorreu o maior valor da FC no período entre $0\left(\mathrm{t}_{0}\right)$ e $20 \mathrm{~s}$ do início do exercício físico e a variação da FC no mesmo intervalo. Para determinar o LA a partir da análise das respostas de FC durante o exercício físico utilizou-se os modelos matemáticos autorregressivos-integrados- médias móveis (ARIMA) e o modelo SMP. Para análise estatística utilizou-se o teste de Wilcoxon, e nas comparações múltiplas o teste de Friedman, seguido do teste de Dunn, e o de correlação de Spearman, com nível de significância de 5\%. 
A FC em repouso na posição sentada foi superior a da posição supina ( $<<0,05)$, já a VFC foi semelhante. $\mathrm{O} t / \Delta \mathrm{FC} \mathrm{t}_{1}-\mathrm{t}_{0}$ e $\mathrm{o} \Delta \mathrm{FC}(\mathrm{bpm})$ apresentou diferenças estatisticamente significantes nas potências realizadas pelos voluntários. Os índices de VFC durante o TEFDD-D reduziram com o incremento de potência apresentando diferenças estatisticamente significantes ( $\mathrm{p}<0,05)$, para o RMSSD nas potências de 55 e $60 \mathrm{~W}$ em relação ao repouso sentado e em relação as potências de 25 e $35 \mathrm{~W}$. O nível do LA foi em 60 W com uma FC de 97 bpm e em 55 W com uma FC de 97 bpm, determinados pelo modelo ARIMA e pelo modelo SMP, respectivamente ( $p>0,05)$. Na comparação dos índices de RMSSD dos IRR no nível de potência do LA determinado pelos modelos de análise, não observamos diferenças significantes ( $p>0,05)$. O coeficiente de correlação entre os índices de RMSSD do modelo SMP vs ARIMA foi rs= 0,82 com $p<0,05$; entre as potências dos dois modelos foi: $r s=0,72, p<0,05$ e entre a $F C$ foi $r s=0,87, p<0,05$. A análise da VFC, a partir do índice de RMSSD foi sensível na identificação de alterações da modulação autonômica sobre o nódulo sinusal. O aumento da FC com concomitante redução da VFC, associado ao incremento de potência sugere uma menor participação da atuação vagal e predomínio da atividade simpática sobre o nó sinusal. As três metodologias de análise utilizadas neste trabalho mostraram respostas similares, apresentando uma correlação estatisticamente significante, sendo portanto adequadas para detectar o ponto de mudança da resposta da FC concomitante ao achatamento da VFC como indicativo do limiar de anaerobiose.

Palavras-chave: limiar de anaerobiose, variabilidade da frequiência cardíaca, exercício físico dinâmico, homens de meia idade, sistema nervoso autônomo. 


\section{ABSTRACT}

TEIXEIRA, L.C.A. Analysis of the pattern of heart rate response by the time series and semiparametric methods and of its variability in the determination of the anaerobic threshold. São Carlos 2003, 69p. Dissertação (mestrado) Escola de Engenharia de São Carlos / Faculdade de Medicina de Ribeirão Preto / Instituto de Química de São Carlos, Universidade de São Paulo.

The objectives of the present study were to assess the heart rate (HR) response and its variability under resting conditions and during dynamic physical exercise, to determine the anaerobic threshold from the analysis of the HR responses during physical exercise using the autoregressive-integrated-moving average (ARIMA) and semi-parametric (SMP) mathematical and statistical models and the indices of heart rate variability (HRV), and to compare the degree of correlation between the three methods of analysis for the detection of changes in the pattern of HR response as an indicator of anaerobic threshold (AT). The study was conducted on 12 volunteers (median age: 42 years) considered to be active and healthy on the basis of clinical and cardiovascular evaluation of resting electrocardiogram (ECG) and of ECG during a continuous dynamic physical effort test of the step type (CDPET-S). The experimental protocol consisted of a discontinuous DPET-S (DDPET-S) with progressive 10 Watts increments starting from and initial power of 25 Watts. RR intervals (RRI) and HR obtained from ECG recordings in real time, beat to beat, were recorded using a signal processing system. The data were obtained in the resting condition for a period of $900 \mathrm{~s}$ with the subject in the supine position, for $900 \mathrm{~s}$ in the sitting position, and with the subject sitting on the bicycle ergometer for $60 \mathrm{~s}$ at rest, for $360 \mathrm{~s}$ while exercising and for 60 s during recovery. We calculated mean HR, RMSSD and RRI indices at rest and during exercise, HRV time $\left(t / \Delta H R t_{1}-t_{0}\right)$ in seconds, where $t_{1}$ is the instant when the highest HR value occurred during the period between $0\left(\mathrm{t}_{0}\right)$ and $20 \mathrm{~s}$ after the beginning of physical exercise, and HR variation $(\Delta \mathrm{HR})$ during the same interval. To determine AT from the analysis of the HR responses during physical exercise we used the ARIMA and SMP models. Data were analyzed statistically by the Wilcoxon test and by the Friedman test for multiple comparisons followed by the Dunn test. Correlation was calculated by the Spearman test and the level of significance was set at 5\% in all analyses. Resting HR in the sitting position was higher than in the supine position $(\mathrm{p}<0.05)$, whereas HRV was similar. 
$\mathrm{t} / \Delta \mathrm{HR} \mathrm{t}_{1}-\mathrm{t}_{0}$ and $\Delta \mathrm{HR}$ (beat/min) presented statistically significant differences at the powers reached by the volunteers. The HRV indices during the DDPET-S were reduced with increasing power, showing statistically significant differences $(p<0.05)$ for RMSSD at the powers of 55 and 60 Watts compared to sitting rest and compared to the powers of 25 and 35 Watts. The AT level determined by ARIMA was at 60 Watts, with HR of 97 beat/min, and the AT level determined by SMP was at 55 Watts, with HR of 97 beat/min ( $>0.05$ ). Comparison of the RMSSD indices of the RRI at the power level of AT determined by the analysis models did not show significant differences $(p>0.05)$. The correlation coefficient between the RMSSD indices of the SMP model vs ARIMA was $r s=0.82$, with $p<0.05$; between the powers of the two models it was $r s=0.72, p<0.05$, and between HR of the two models it was rs $=0.87, \mathrm{p}<0.05$. HRV analysis from the RMSSD index was sensitive for the identification of changes in autonomic modulation of the sinus node. The increase in HR with a concomitant reduction in HRV, together with the increment in power suggests a lower participation of vagal activity and a predominance of sympathetic activity in the sinus node. The three methods used for analysis in the present study showed similar responses and were strongly correlated and therefore are adequate to detect the point of change in the HR response concomitant with HRV flattening as an indication that AT.

Key words: anaerobic threshold; heart rate variability; dynamic physical exercise; middleaged men, autonomic nervous system. 


\section{INTRODUÇÃO}

Durante o exercício físico ocorrem alterações complexas nos processos biológicos dos organismos vivos, originando um grande número de ajustes fisiológicos dinâmicos que integram todos os sistemas biológicos. Esses ajustes dependem da eficácia dos sistemas cardiovascular, respiratório, sangüíneo (hemoglobina) e muscular em atividade contrátil, adequando a utilização do oxigênio para manter ao longo do tempo a formação de ATP e restaurar as reservas que foram consumidas durante a fase anaeróbia. Além disso, é responsável pela remoção do gás carbônico $\left(\mathrm{CO}_{2}\right)$ produzido como resultado bioquímico final. Os mecanismos responsáveis pela regulação da função cardiovascular durante o exercício físico são controlados por estruturas organizadas em alto grau hierárquico, com centros localizados no sistema nervoso central, denominada de tracto solittarius, localizada na medula oblonga (McARDLE, et al., 1996).

As informações a partir das quais o sistema regulador promove ajustes cardiovasculares, de acordo com as demandas fisiológicas, provém de três vias: atuações de um comando central a partir de centros motores superiores, originando descarga aferente aos neurônios do bulbo (BARROS NETO, 1996); descargas aferentes a partir de terminações nervosas musculares de fibras dos grupos III e IV, sensíveis a estímulos mecânicos e ou metabólicos locais diretamente relacionados à natureza e intensidade do exercício (MITCHELL, 1983) e o comando cardiodinâmico (WASSERMAN \& WHIPP, 1983), por meio do qual o retorno venoso e mais exatamente o fluxo de $\mathrm{CO}_{2}$ aos pulmões originariam informações aferentes necessárias aos ajustes cardioventilatórios do exercício. 
O eferente parassimpático (vago) conduz estímulos para o nódulo sinoatrial e o átrio ventricular e para o miocárdio atrial. A inervação simpática distribui-se por todas as áreas do sistema circulatório, incluindo o miocárdio ventricular, os tecidos de condução especializados e o músculo liso das paredes das artérias e veias. A forte interação entre o parassimpático e o simpático cardíaco resultará em importante oscilação da FC (RIBEIRO, 2001b).

As respostas cardiovasculares ao exercício físico podem ser influenciadas por fatores diversos como: aqueles ligados a características antropométricas (peso, altura e área de superfície corporal); sexo; idade; características genéticas; hábitos alimentares (quantidade e qualidade dos alimentos); nível de aptidão física; estado de saúde; ingestão de bebidas alcoólicas; fumo; ciclo circadiano (horário do dia); condições ambientais em que o exercício é realizado (temperatura, altitude, umidade relativa do ar); tipo de instrumental utilizado; tipo de exercício realizado (dinâmico ou isométrico); quantidade de massa muscular envolvida; percentual da força de contração, duração da contração, ângulo da articulação, posição corporal em que o exercício é realizado e protocolo experimental utilizado (ASTRAND \& RODAHL, 1980; GALLO JR et al., 1990; GALLO JR et al., 1995, CATAI et al., 1996; CATAI, 1999, SILVA et al., 1998).

Durante o exercício físico a FC sofre constantes modificações, moduladas pelo sistema nervoso autônomo e a partir da análise do seu padrão de resposta pode-se obter indiretamente informações do comportamento de sua variabilidade (RIBEIRO et al., 2001).

Vários estudos, utilizando-se de bloqueios farmacológicos ou não (ROBINSON et al., 1966, CUMMING \& CARR, 1967; EKBLOM et.al., 1968; MACIEL et. al., 1986, GALLO JR et. al., 1988; 1995; SEALS \& VÍCTOR, 1991), demonstraram que durante o exercício físico dinâmico independente da intensidade de potência aplicada, ocorre um rápido aumento inicial da FC, que se deve à inibição do componente parassimpático (vago) sobre o nódulo sinusal, alcançando valor pico por volta dos primeiros 10 a 20s. Após o primeiro minuto de exercício, documenta-se uma diminuição ou estabilização de seus valores que é dependente da retomada 
vagal. Documenta-se ainda que o predomínio da estimulação simpática sobre o nódulo sinusal, acarreta uma elevação lenta da FC, observada em níveis mais elevados de exercício e é proporcional ao incremento da potência aplicada (MACIEL et al., 1986; GALLO JR et al., 1987; CATAI, 1992; GALLO JR et al., 1995; CHACON-MIKAHIL et al., 1998; SILVA, 1988, MARÃES, 1999).

\subsection{Limiar de Anaerobiose}

O limiar de anaerobiose ou limiar anaeróbio (LA) tem sido referido como a intensidade de trabalho ou de consumo de oxigênio $\left(\dot{\mathrm{V}} \mathrm{O}_{2}\right)$ em que o metabolismo durante o exercício é alterado, ou seja, é o momento durante o exercício crescente em que a produção de ATP passa a ser em decorrência de um predomínio crescente da via glicolítica, alterando a relação entre a taxa de produção e remoção do ácido lático, gerando acúmulo do mesmo (WASSERMAN \& McLLROY, 1964; DAVIS et al., 1979; FARREL, et al., 1979; KINDERMAN et al., 1979; GREN et al., 1983; SIMON et al., 1983, DAVIS, 1985; KOIKE et al., 1990).

Nos últimos 20 anos, houve um aumento do interesse pelo estudo do LA na avaliação da performance física e tem sido utilizado como ferramenta para prescrição dos protocolos de treinamento e auxílio no diagnóstico de certas patologias (WASSERMAN, 1999).

Desde a década de 70, a identificação do momento do LA, foi incluída como parte de um protocolo padrão por muitos cardiologistas, pneumologistas e em laboratórios de fisiologia do exercício. Para pacientes com patologias cardiorespiratórias, o LA pode ser utilizado como uma medida direta da carga de trabalho em que o sistema cardiovascular começa a limitar a oferta de oxigênio aos tecidos ativos.

Nas intensidades de trabalho físico abaixo do LA, existe um equilíbrio dinâmico entre a produção do ácido lático pelas células do organismo e a reconversão do ácido lático pela neoglicogênese. No momento do LA, a produção do lactato pelas células musculares metabolicamente ativas se iguala à remoção feita 
pela musculatura inativa, pelos rins, pelo coração e principalmente pelo fígado (STAINSBY et al., 1991; TEGTBUR, 1993). Nesse momento o lactato está no ponto máximo do equilíbrio dinâmico, onde a remoção de lactato está igualada à produção. A partir do LA, a produção de ácido lático passa a ser superior a sua remoção e há perda da condição de equilíbrio dinâmico no exercício (JORFELDT, et al., 1978; BROOKS, 1991). Com alteração do equilíbrio ácido-base instala-se uma acidose metabólica, o que leva os sistemas fisiológicos a aumentarem seus desempenhos para a manutenção da homeostase celular e, assim, da atividade física (KOIKE et al., 1990). TEGTBUR et al. (1993) referem que o máximo equilíbrio dinâmico entre produção e remoção do lactato, ocorre no nível do LA onde há o pico de $\dot{V}_{2}$ com predomínio das vias metabólicas oxidativas.

O LA pode ser identificado por vários métodos, os invasivos e/ou os não invasivos. WASSERMAN (1984) refere que há um crescimento acentuado do lactato plasmático, de forma exponencial, no momento do LA e refere ainda um método direto e não invasivo na determinação do LA por meio da análise das variáveis ventilatórias $\left(\dot{\mathrm{V}} \mathrm{CO} 2, \dot{\mathrm{V}} \mathrm{O}_{2}\right.$ e $\left.\dot{\mathrm{V}} \mathrm{E}\right)$. Segundo este autor durante a realização de exercício dinâmico contínuo e incremental observa-se nestas variáveis pontos de mudanças que podem ser caracterizados como o momento do LA.

A identificação do LA por método invasivo, pode ser realizada a partir da dosagem da concentração de ácido láctico sangüíneo coletado por cateteres em veias (STAMFORD et al., 1981; CAIOZZO et al., 1982) ou artérias (KNUTTGEN, 1962; WASSERMAN et al., 1964; EKBLON. et al., 1968) ou, através de pequenas amostras obtidas da polpa dos dedos (BELCASTRO \& BONEN, 1975) ou do lóbulo da orelha (BUNC et al., 1995).

Mais recentemente tem sido referido na literatura que o LA pode ser determinado a partir do estudo da modulação autonômica do coração por meio da análise das respostas da FC e de sua variabilidade. Utilizando-se de modelos matemáticos e estatísticos de séries temporais e semiparamétricos ajustados aos dados de FC e índices de VFC (RMSSD), que permitem a detecção da perda da estabilidade da FC bem como a diminuição da sua variabilidade, durante o exercício 
físico dinâmico descontínuo do tipo degrau, caracterizando o nível de potência em que ocorre o LA (MARÃES et.al., 1996; GARCEZ et al., 2000; MARÃES, 1999; MARÃES et.al., 2000b; SAKABE et al., 2002).

ALONSO et. al. (1998), estudando o efeito do impacto metabólico sobre o comportamento de FC e de sua variabilidade (VFC), durante exercício físico progressivo máximo, verificaram um aumento da FC concomitante ao da intensidade de esforço e uma diminuição progressiva da VFC até a intensidade do exercício em que foi caracterizado o LA. A partir desse ponto, os autores observaram que a VFC mantém-se inalterada, sugerindo que a sua diminuição ocorre em fases do exercício onde há o predomínio do metabolismo anaeróbio concomitantemente ao aumento da FC, mediada pela diminuição crescente da atividade vagal e predomínio da atividade simpática.

Como pode ser observado, o LA, além de ser um delimitador de mudanças fisiológicas, altera a atividade do sistema nervoso autônomo, principalmente da eferência simpática sobre o coração e os vasos sangüíneos, modificando as respostas cardiovasculares (GALLO JR et. al., 1996).

Neste trabalho vale ainda observarmos que o processo do envelhecimento promove modificações autonômicas do controle cardiovascular, caracterizada principalmente por uma diminuição do tônus vagal, e conseqüentemente, diminuição na VFC na condição de repouso (CHACONMIKAHIL et al., 1998; CHACON-MIKAHIL, 1998; CATAI, 1999; CATAI et. al., 2000 e 2002; RIBEIRO, 2001a). Além disso, o envelhecimento leva a um declínio fisiológico das funções orgânicas, decorrentes principalmente das alterações estruturais que ocorrem nos sistemas biológicos com o passar da idade.Tais alterações levam a uma redução na capacidade física dos indivíduos, caracterizada, principalmente, pela redução de parâmetros cardiovasculares, tais como: consumo máximo de oxigênio, FC máxima e diferença arterio-venosa de oxigênio, quando o indivíduo é submetido a um exercício físico aeróbio (CATAI, 1999; CATAI et. al., 2000; MARÃES, 1999). 
Tendo por base os trabalhos levantados até o momento, é que a presente investigação se justifica, no sentido de trazer contribuições adicionais enfocando metodologias não invasivas na detecção do LA. 


\section{OBJETIVOS}

O presente trabalho tem como objetivos:

Avaliar a resposta da FC e de sua variabilidade nas condições de repouso e em exercício físico dinâmico.

Determinar o LA a partir da análise das respostas de FC durante o exercício físico pelos modelos matemáticos autorregressivos-integrados-médias móveis (ARIMA), semiparamétrico e pelos índices de VFC.

Comparar o grau de correlação entre as três metodologias de análise na detecção de alterações no padrão de estabilidade da resposta da FC como indicador do LA. 


\section{MATERIAIS E MÉTODOS}

\subsection{Voluntários estudados}

Foram estudados 12 voluntários saudáveis, do sexo masculino, não fumantes, com idades compreendidas entre 40 e 50 anos (mediana 42 anos) e com padrão ativo de vida, baseado nas respostas do teste ergométrico clínico e das atividades esportivas realizadas, em mediana de 3,5 horas semanais, com predominância de exercício físico dinâmico.

As características antropométricas, idade e os dados das avaliações estão expressos nas tabelas 1 e 2 (apêndice 2).

\subsection{Aspectos éticos}

Este estudo foi aprovado pela Comissão de Ética em Pesquisa da UFSCar (apêndice 1).

Todos os voluntários foram previamente esclarecidos e orientados a respeito de suas participações nos testes, do caráter não invasivo dos mesmos bem como quanto aos procedimentos utilizados. Após concordarem em participar do estudo, todos os voluntários assinaram um termo de consentimento formal, de acordo com as normas do Conselho Nacional de Saúde (apêndice 1).

Os voluntários foram familiarizados com o ambiente experimental, com os experimentos e com os pesquisadores envolvidos. 


\subsection{Avaliação clínica}

Os voluntários foram submetidos a uma anamnese e exame físico, investigando-se os hábitos de vida e alimentar, história pregressa e existência passada de patologias conforme ficha de avaliação adaptada de SILVA \& CATAI (1991); foi realizado um eletrocardiograma (ECG) convencional de 12 derivações na posição supina em repouso e nas derivações MC5, DII e V2 modificadas, nas posições supina, sentada e em hiperventilação (sentado) durante $30 \mathrm{~s}$; durante este período de registro foram verificadas a FC a partir do ECG e a pressão arterial (PA) pelo método auscultatório.

Como critério para inclusão do voluntário no estudo, exigiu-se que o ECG em repouso não apresentasse alterações.

Todos os voluntários foram submetidos a um teste de exercício físico dinâmico contínuo do tipo degrau (TEFDC-D), com a finalidade de avaliação clínica e cardiovascular. Durante este teste, os voluntários foram monitorizados nas derivações MC5, DII e V2 modificadas. O protocolo do TEFDC-D foi realizado na posição sentada em cicloergômetro eletromagnético, sendo inicialmente aplicado 4 $\mathrm{W}$ de potência por um período de 2 min e posteriormente incrementos de 25 em 25 W a cada $3 \mathrm{~min}$, até a exaustão física ou surgimento de sinais e/ou sintomas limitantes. A FC, PA e o ECG foram registrados antes do início do esforço, nos $30 \mathrm{~s}$ finais de cada nível de esforço, e ao final do teste no $1^{\circ}, 3^{-}, 6^{\circ}$ e $9^{-}$min de recuperação.

Os voluntários foram submetidos a exames laboratoriais: colesterol total e frações, triglicérides, glicemia, hemograma completo, urina tipo1 e uréia.

Foram incluídos no presente estudo os voluntários que não apresentaram quaisquer anormalidades às avaliações e aos exames acima mencionados. 


\subsection{Procedimentos gerais}

Os testes foram realizados no Laboratório de Fisioterapia Cardiovascular da Universidade Federal de São Carlos - Núcleo de Pesquisa em Exercício Físico. Os protocolos experimentais foram sempre realizados no mesmo horário, levando-se em consideração as influências do ritmo circadiano e, se em período pós-prandial, observou-se um intervalo de 2 a 3 horas após uma refeição leve.

Foi mantido um número mínimo de pessoas na sala experimental, para não interferir no estado emocional dos voluntários.

As condições ambientais da sala experimental foram controladas e mantidas em uma temperatura média de $22,75 \pm 0,86{ }^{\circ} \mathrm{C}$ e uma umidade relativa do ar média de $61 \pm 5,77 \%$.

Os voluntários foram orientados para que 24 horas antes dos testes não utilizassem bebidas alcoólicas e/ou estimulantes (café, chá e outros), não realizassem esforços físicos, não utilizassem medicamentos, fizessem uma refeição leve pelo menos duas horas antes dos testes e se apresentassem com roupas e calçados confortáveis para a execução da atividade física.

A preparação dos equipamentos, dos materiais e a organização da sala foram realizadas antes da chegada de cada voluntário. Com intuito de reduzir a ansiedade e a expectativa por parte dos voluntários, todos foram familiarizados com todos os equipamentos e protocolos utilizados, antes da realização dos mesmos.

Foram verificadas as condições do voluntário, em relação ao seu estado de saúde, no dia da realização dos testes experimentais. Os voluntários foram orientados para que durante os testes no cicloergômetro não realizassem contrações isométricas com os membros superiores ao segurar o guidão, não falassem desnecessariamente com os avaliadores para evitar alterações nos traçados eletrocardiográficos e que informassem sobre qualquer alteração percebida no seu estado geral como: mal-estar, dor no peito, fadiga (dor muscular), tontura, turvação 
visual, ânsia de vômito ou surgimento de outros sintomas limitantes que impossibilitassem a continuidade dos testes.

Os voluntários realizaram os testes em cicloergômetro de frenagem eletromagnética (Quinton - Corival 400), com a altura do banco regulado de modo a permitir uma flexão de joelho de aproximadamente 15 graus, com o pé na porção mais baixa do pedal. Os voluntários foram orientados a manter a velocidade em torno de 60 rotações por minuto (rpm). As potências de exercício físico foram aplicadas por meio de um microprocessador de potência em Watts, modelo Workload Programm, da marca "Quinton" (Groningen, Netherlands), que permitia a préprogramação do protocolo utilizado ou pela aplicação das potências manualmente.

\subsection{Protocolo experimental}

\subsubsection{Teste de exercício físico dinâmico descontínuo do tipo degrau (TEFDD-D) com potências progressivas}

Este protocolo foi padronizado com o objetivo de avaliar a modulação autonômica do coração nas condições de repouso e em exercício físico como já estabelecido por outros trabalhos (LINNARSON, 1974; MACIEL, 1986; SILVA, 1988) assim como avaliar o LA (BALDISSERA, 1992).

Previamente ao teste, foi feita a captação do ECG na derivação MC5 para obtenção da FC, dos IRR, em repouso, nas posições supina e sentada, por 900s, em cada posição. Após esse período, o voluntário ativamente sentava-se no cicloergômetro eletromagnético, e o pesquisador aguardava alguns minutos até que os valores de FC retornassem aos valores basais e, a seguir, dava-se início ao registro da FC por um período de 60 s em repouso antes, durante 360 s da realização do exercício físico e nos 60s na fase de recuperação (figura 1) após cada potência.

O TEFDD-D foi iniciado com uma potência de $25 \mathrm{~W}$. A partir desta os incrementos de potências foram de $10 \mathrm{em} 10 \mathrm{~W}$. Entre uma potência e outra foi 
interposto um período variável de repouso para que a FC retornasse aos seus valores basais. Em cada nível de potência foram observados visualmente o padrão de resposta da FC e a ocorrência da inclinação desta variável. A partir da potência em que foi observada a inclinação da FC, foram realizados 2 níveis de esforço onde para um se reduzia $5 \mathrm{~W}$ e no outro aumentava $5 \mathrm{~W}$. 


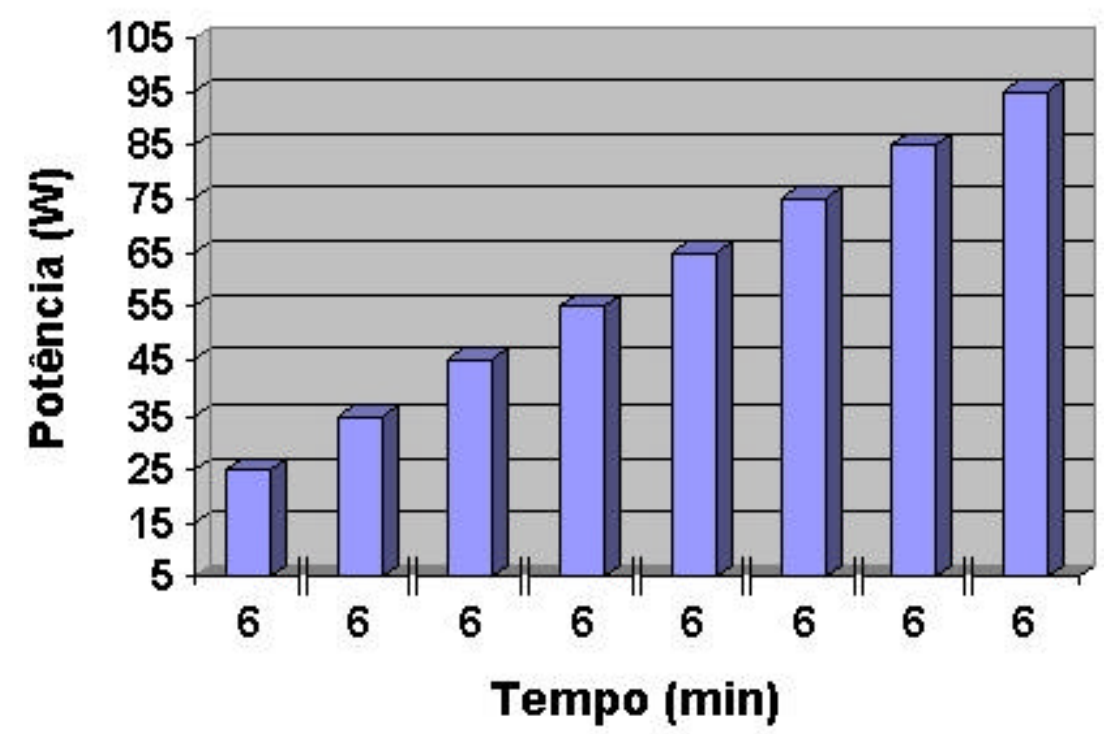

Figura 1. Representação esquemática do teste de exercício físico dinâmico descontínuo do tipo degrau (TEFDD-D), com potências progressivas de incrementos de 10 Watts (W), duração de 6 minutos e com períodos variáveis de repouso, interpostos entre níveis de exercício físico.

Durante o TEFDD-D utilizourse um monitor cardíaco de 1 canal (TC500, ECAFIX) para a visualização do sinal eletrocardiográfico. A FC foi obtida a partir dos sinais do ECG convencional, captados por intermédio de um conversor analógico digital Lab-PC+ (National Instruments, Co), que se constituiu numa "interface" entre o monitor cardíaco e o microcomputador Pentium III. A partir da "interface”, o sinal analógico do ECG era convertido em valores binários para o acesso no microcomputador, por meio de um programa de processamento de sinais digitalizados (SILVA et al., 1994). A partir do ECG, os IRR foram calculados pelo programa, bem como os valores instantâneos de FC em batimentos por minuto (bpm); tais valores eram amostrados em tempo real por meio da visualização gráfica, (figura 2) e armazenados em disco, para posterior análise dos dados e impressão dos relatórios.

Os sinais de ECG foram captados a partir de eletrodos de carbono ativado, auto-adesivos e descartáveis posicionados na seguinte configuração: pólo negativo no manúbrio esternal, ao nível do $3^{0}$ espaço intercostal, o positivo na região

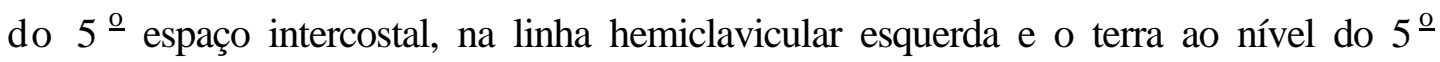


espaço intercostal direito . A posição dos eletrodos foi modificada para prevenir possíveis interferências na captação do sinal eletrocardiográfico e também se obter uma maior diferença entre $\mathrm{o}$ pico de onda $\mathrm{R}$ e da onda $\mathrm{T}$ nos registros eletrocardiográficos.

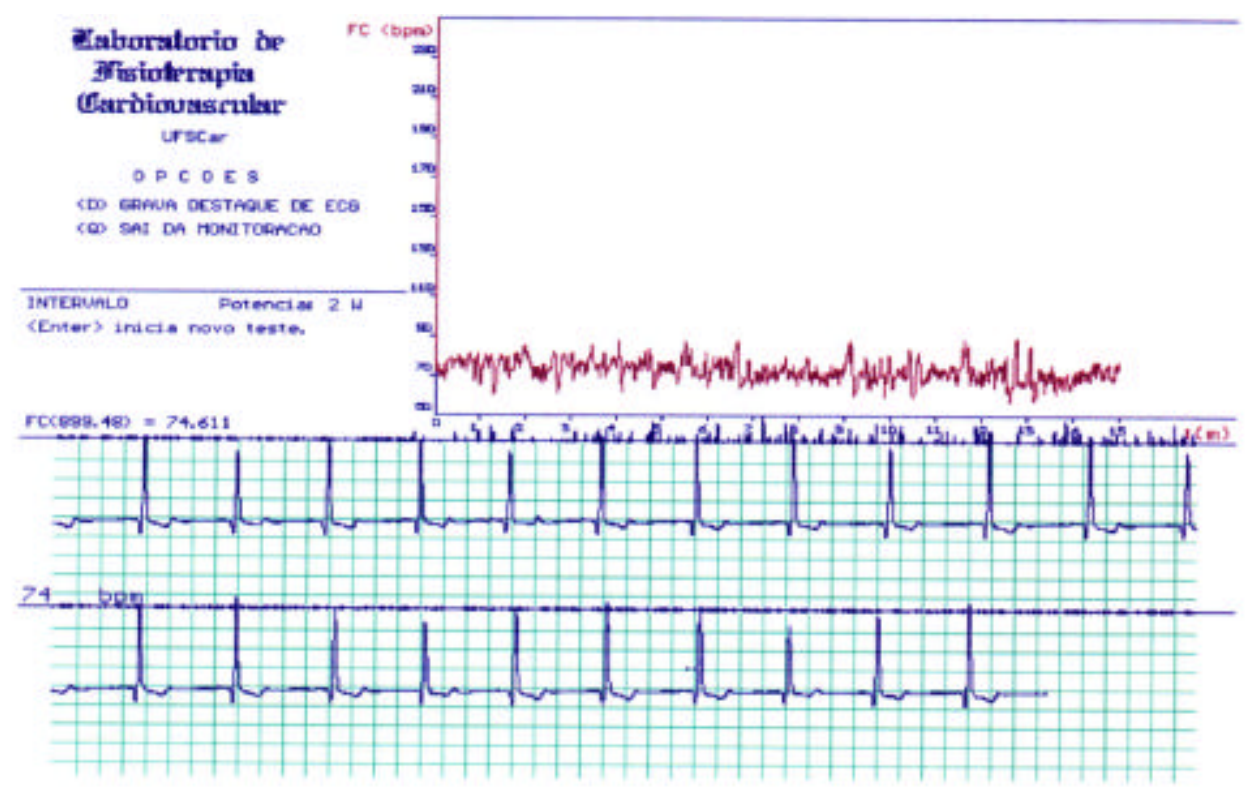

Figura 2. Ilustração da tela do computador durante a aquisição do ECG e da freqüência cardíaca (FC), batimento a batimento, em tempo real, durante o repouso na posição sentada, de um dos voluntários estudados (FMM).

\subsection{Métodos de análise no domínio do tempo}

\subsubsection{Análise da freqüência cardíaca}

\subsubsection{Nas condições de repouso}

A FC e os IRR foram captados e armazenados, em tempo real, batimento a batimento, durante $900 \mathrm{~s}$ em repouso nas posições supina e sentada. Foram calculadas a FC média de repouso de cada voluntário e expresso em valores médios. 


\subsubsection{Nas condições de exercício físico dinâmico descontínuo}

Foram calculados os valores numéricos derivados da FC (FC média do 60s em repouso pré-teste; FC pico no intervalo de 0 a 20s de exercício dinâmico) para cada um dos voluntários estudados nas potências de 25, 35, 45, 55 e 65Watts.

$$
\ddot{\mathrm{AFC}}=\mathrm{FC}_{\text {PICO }}-\overline{\mathrm{FC}}_{\mathrm{REPOUSO}}
$$

Foram também calculados: a) o tempo de variação da FC (t/DFC), em segundos, que corresponde a diferença entre o instante que ocorreu a FC pico $\left(t_{1}\right)$, no intervalo de 0 a $20 \mathrm{~s}$ de exercício dinâmico, e b) o tempo em segundos, em que se iniciou o exercício $\left(\mathrm{t}_{0}\right)$ (equação 2$)$.

$$
\frac{\mathrm{t}}{\ddot{\mathrm{AFC}}}=\mathrm{t}_{1}-\mathrm{t}_{0}
$$

\subsubsection{Análise da variabilidade da frequiência cardíaca}

Para análise da variabilidade da FC em repouso e durante o teste de exercício físico dinâmico descontínuo foi utilizado o índice temporal RMSSD dos IRR em milissegundos (ms).

$\mathrm{O}$ índice RMSSD, corresponde à raiz quadrada da somatória do quadrado das diferenças entre os IRR sucessivos no registro divididos pelo número de IRR em 900 segundos em repouso e 240 segundos em exercício físico menos um (ANTILA, 1979), para todos os voluntários (Eq.3). 


$$
R M S S D=\sqrt{\frac{\sum_{i=1}^{N-1}\left(I R R_{i}-I R R_{i+1}\right)^{2}}{N-1}}
$$

Onde:

$\mathrm{IRR}=$ intervalos RR e

$\mathrm{N}$ = número de intervalos RR na série de dados selecionados.

Para o tabelamento e cálculo desses índices utilizou-se o programa

"Analisador Gráfico de Intervalos R-R, (IRR), Freqüência Cardíaca (FC) e Eletrocardiograma (ECG)" desenvolvido no Laboratório de Fisioterapia Cardiovascular (GOUVÊA et al., 1998), como exemplificado na figura 3.

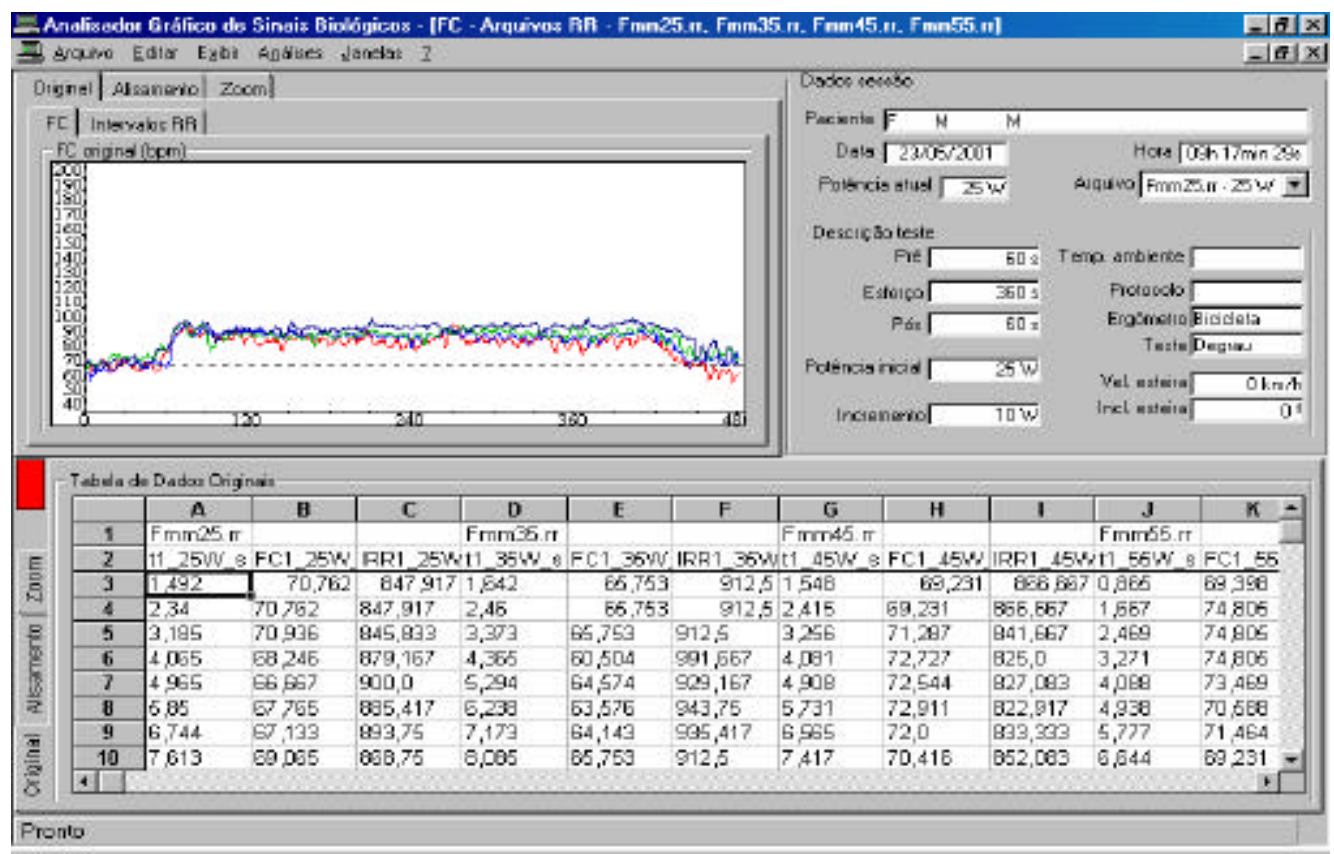

Figura 3. Ilustração da tela do computador do programa "Analisador Gráfico de IRR, FC e ECG” contendo informações do protocolo utilizado, planilha de dados absolutos de iRR e de FC batimento a batimento, gráficos das respostas de FC em exercício físico dinâmico. 


\subsection{Análise da resposta da freqüência cardíaca na determinação do limiar de anaerobiose (LA)}

\subsubsection{Ajuste do modelo matemático e estatístico semiparamétrico ao conjunto de dados de freqüência cardíaca obtidos durante o TEFDD-D}

O LA pode ser caracterizado a partir da resposta da FC durante um teste de exercício físico dinâmico descontínuo, como sendo o momento em que ocorre a perda de sua estabilidade. Para a análise em questão, na sequiência da série de dados de FC tabelados, foi selecionado o intervalo mais estável durante o exercício físico no período de registro entre 180 a 420s, utilizando-se um modelo semiparamétrico, matemático e estatístico a partir de uma rotina desenvolvida para este fim (OLIVEIRA, L., et. al., 2002) utilizando-se do aplicativo "S-Plus" (Versão 4.5 Professional Release 2 for MS Windows, 1998, Copyright (C) Statistical Sciences, Inc. Copyright AT \& T).

Na figura 4 está representado o resultado da análise dos dados de FC no intervalo de 200 a 400s (trecho estável dos dados obtidos de um dos voluntários estudados) do período de exercício físico na potência de $85 \mathrm{~W}$. 


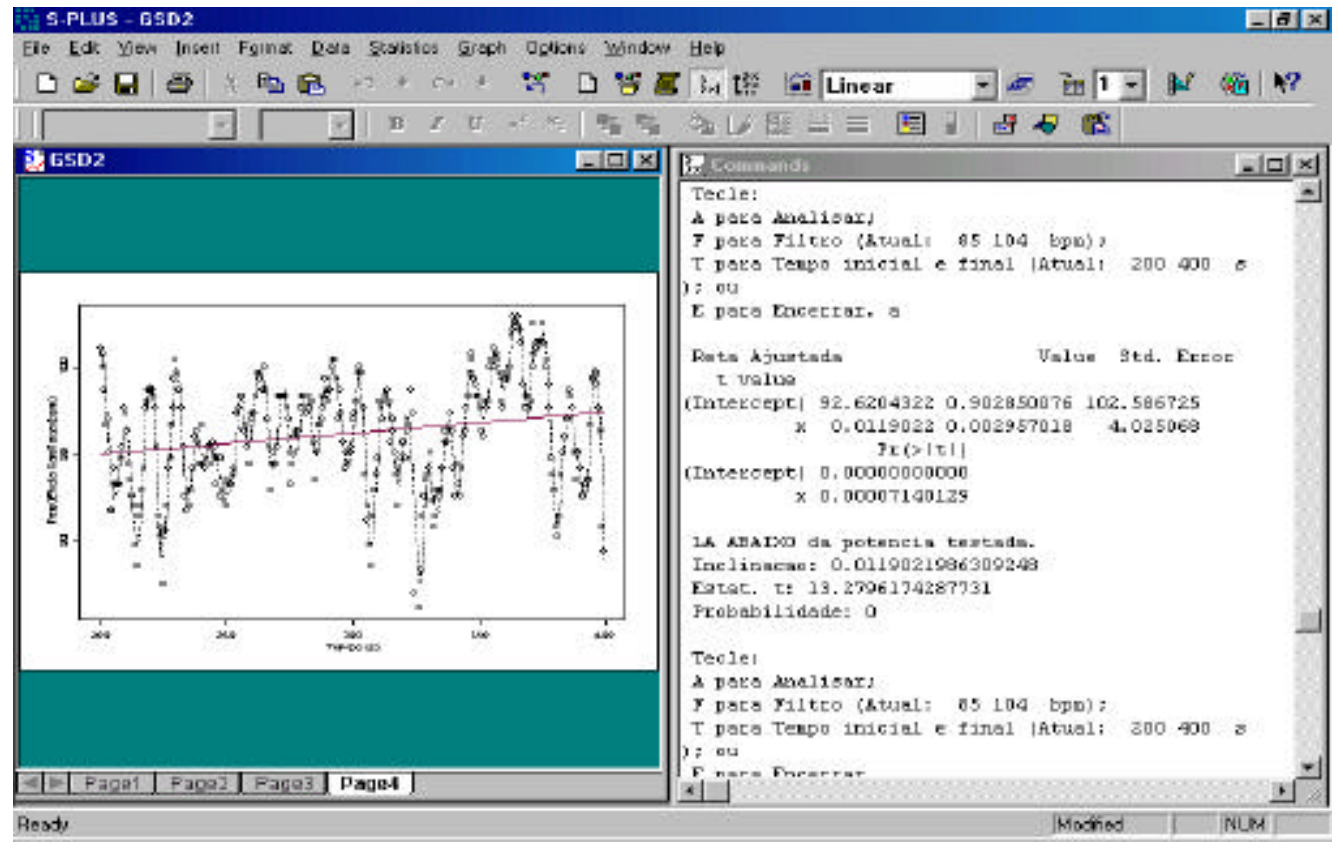

Figura 4. Ilustração de um gráfico do conjunto de dados de $\mathrm{FC}$ e o relatório contendo os dados da série ajustada pelo modelo semiparamétrico, na potência de $85 \mathrm{~W}$, considerado como o nível do LA de um dos voluntários estudados (JRM).

\subsubsection{Ajuste dos modelos autorregressivos integrados médias móveis (ARIMA)}

Para determinar o LA através das respostas da FC obtida dos TEFDDD, utilizou-se ainda a metodologia de BOX-JENKINS (1970) que exige eqüidistância nos dados de FC. Fez-se necessário o alisamento dos dados (médias de 2 em 2 s) utilizando-se um aplicativo "Analisador Gráfico de Eletrocardiograma" (GOUVÊA et al., 1998) no intervalo de 180 a 420 segundos de exercício físico para então serem analisados por meio dos modelos autorregressivos-integrados-médias móveis (ARIMA).

O modelo ARIMA foi aplicado ao conjunto de dados de FC para descrever o comportamento da série ou fazer previsões sobre a perda da estabilidade da mesma 


\subsection{Metodologia estatística}

Para se escolher o tipo de teste estatístico a ser empregado (paramétrico ou não paramétrico) procedeu-se a uma avaliação quanto aos tipos de distribuição das variáveis estudadas em diferentes condições. O procedimento de análise de distribuição dos dados (figura 5) mostrou que os mesmos não possuíam distribuição normal. Portanto, foram utilizados testes estatísticos não paramétricos.

A análise descritiva dos resultados de FC e dos IRR foi apresentada graficamente em Box-Plots contendo os valores da mediana, $1^{\circ}$ quartil $(25 \%), 3^{\circ}$ quartil (75\%), valores máximos e mínimos, “outliers” e extremos.

A análise de significância estatística procedeu-se a partir da aplicação de testes não paramétricos, sendo o teste de Wilcoxon para amostras pareadas, teste de Friedman para medidas repetidas seguidas de técnicas de comparações múltiplas pelo Teste de Dunn. O nível de significância estabelecido para todos os procedimentos estatísticos foi de $\alpha=0,05$.

O coeficiente de correlação de Spearman $\left(\mathrm{r}_{\mathrm{s}}\right)$ foi calculado para verificar as associações entre as seguintes variáveis estudadas: potências em Watts, FC em bpm e para o índice RMSSD dos IRR em ms atingidos no momento do LA. Foi utilizado o aplicativo "STATISTICA" for Windows, Release 5.5. StatSoft, Inc. (2000) e “GraphPad InStat” for Windows Versão 3.0 (1994-1999). 

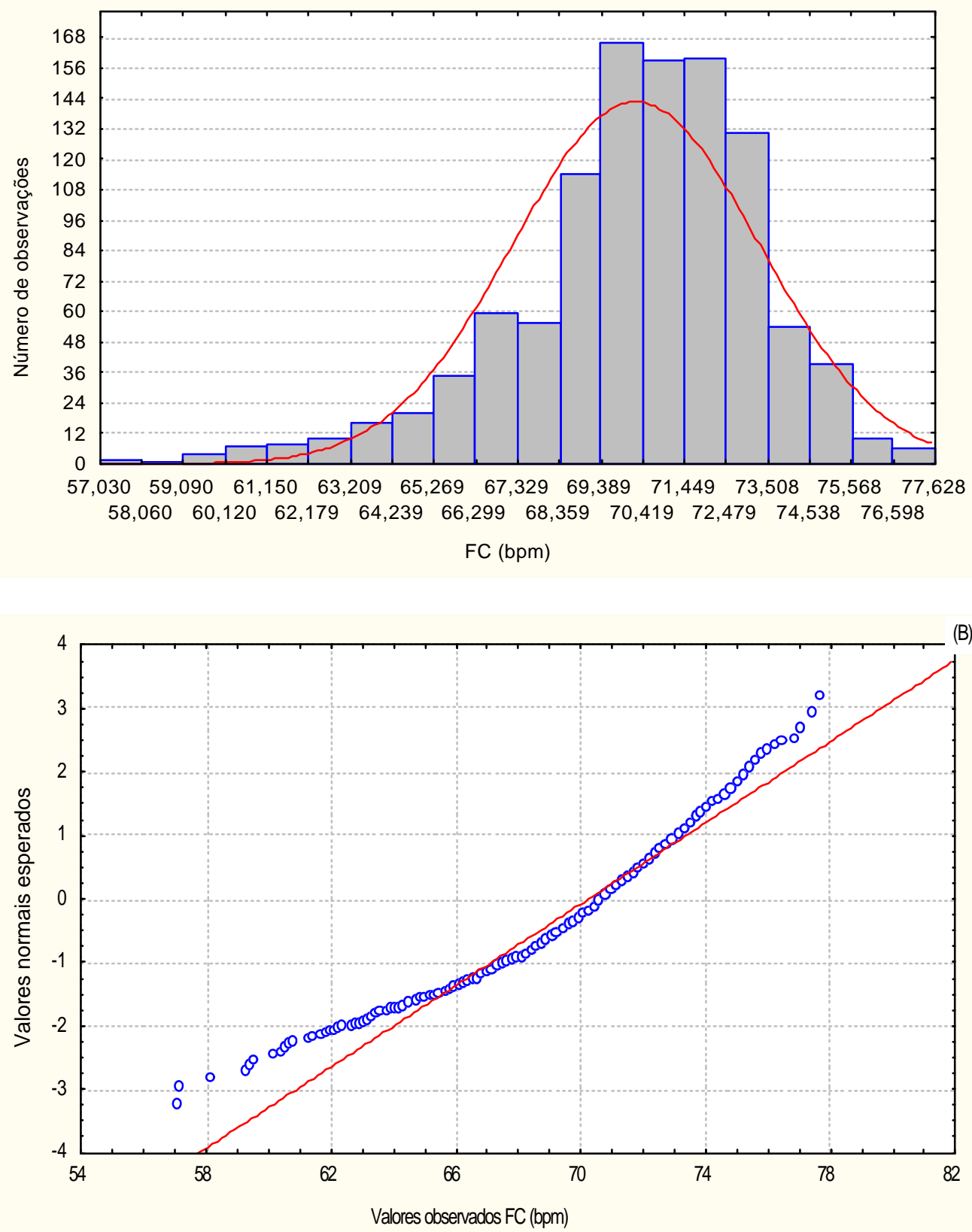

Figura 5. Análise dos valores absolutos de freqüência cardíaca, em batimentos por minuto (bpm), durante a condição de repouso na posição sentado, de um dos voluntários estudados quanto à distribuição dos dados. Em (A) estão representados a curva de Gauss e o histograma do número de observações e em (B) estão representados os valores observados em relação aos valores esperados. 


\section{RESULTADOS}

\subsection{Voluntários estudados}

No presente texto os dados dos voluntários relativos a idade $\mathrm{e}$ características antropométricas estão apresentados na tabela 1 (apêndice 1), e os valores das variáveis cardiovasculares (pressão arterial sistólica, pressão arterial diastólica ambas em milímetros de mercúrio ( $\mathrm{mmHg}$ ), FC (bpm), tipo de atividade física e horas semanais estão expostos na tabela 2 (apêndice 1). Os dados estão apresentados em valores de tendência central, referidos sempre em mediana.

A idade mediana dos voluntários estudados foi de 42 anos, a altura de 173 centímetros, o peso corporal foi de $76 \mathrm{~kg}$ e o índice de massa corporal foi de $26,01 \mathrm{Kg} / \mathrm{m}^{2}$. Verifica-se na tabela 2 (apêndice 1) que os valores medianos das variáveis cardiovasculares dos voluntários apresentavam-se dentro do padrão de normalidade, ou seja, a FC na posição supina em repouso foi de 64 bpm, a pressão arterial sistólica de $112 \mathrm{mmHg}$ e a pressão arterial diastólica de $75 \mathrm{mmHg}$.

Os voluntários foram classificados como ativos, pois os mesmos realizavam atividades físicas de natureza recreacional ou de lazer (caminhada, corrida, ginástica aeróbia, ciclismo: 3,5 horas semanais).

\subsection{Análise descritiva e no domínio do tempo da freqüiência cardíaca em repouso}

A FC e sua variabilidade (VFC) foram estudadas em repouso e durante o teste de exercício físico dinâmico descontínuo. 


\subsubsection{Frequiência cardíaca em repouso}

A figura 6 representa a resposta da FC, obtida batimento a batimento, por processamento "on line" em tempo real de um dos voluntários na condição de repouso na posição supina e sentada por um período de 900 segundos, em cada uma das posições, antes da execução dos TEFDD-D.

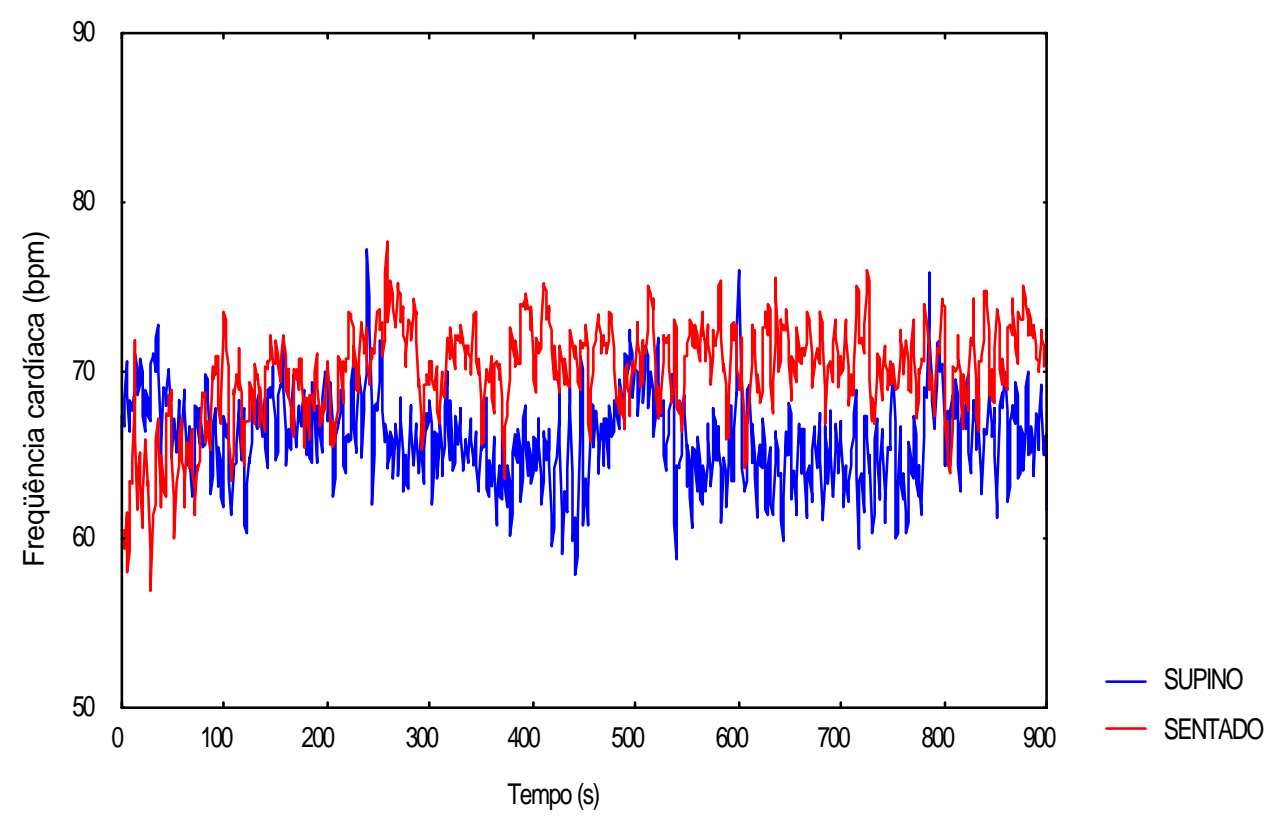

Figura 6. Frequiência cardíaca, obtida batimento a batimento, em tempo real, em repouso nas posições supina e sentada, durante 900s, antes da execução dos testes de exercício físico dinâmico descontínuo do tipo degrau (TEFDD-D) de um dos voluntários (FMM).

Pela análise descritiva visual (figura 6) e pela análise estatística (figura 7) verificou-se que a FC na posição supina apresenta menores valores em relação aos da posição sentada, apresentando diferença estatisticamente significativa $(\mathrm{p}<0,05)$. 


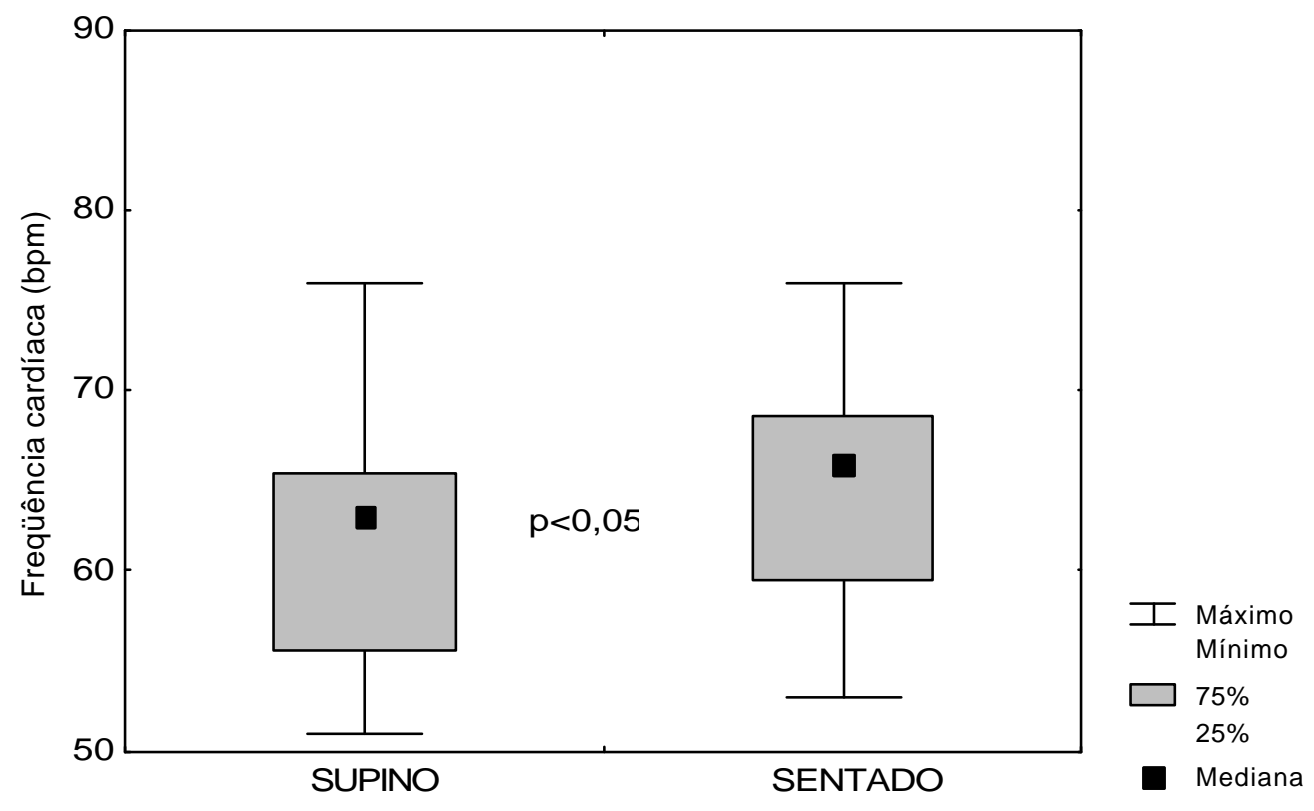

Figura 7. Frequiência cardíaca média, em batimentos por minuto (bpm), observados durante um período de 900 segundos de repouso, nas posições supina e sentada $(\mathrm{N}=12)$. Nível de significância á = 0,05.

\subsubsection{Variabilidade da frequiência cardíaca em repouso}

Ao se analisar o índice RMSSD dos IRR em ms (figura 8), obtido na condição de repouso nas posições supina e sentada (tabela 4), verifica-se que não houve diferenças estatisticamente significantes $(p>0,05)$ da VFC. Quanto à variabilidade dos dados (distância entre $1^{\circ}$ e $3^{\circ}$ quartis) observa-se que esta foi superior na posição sentada. 


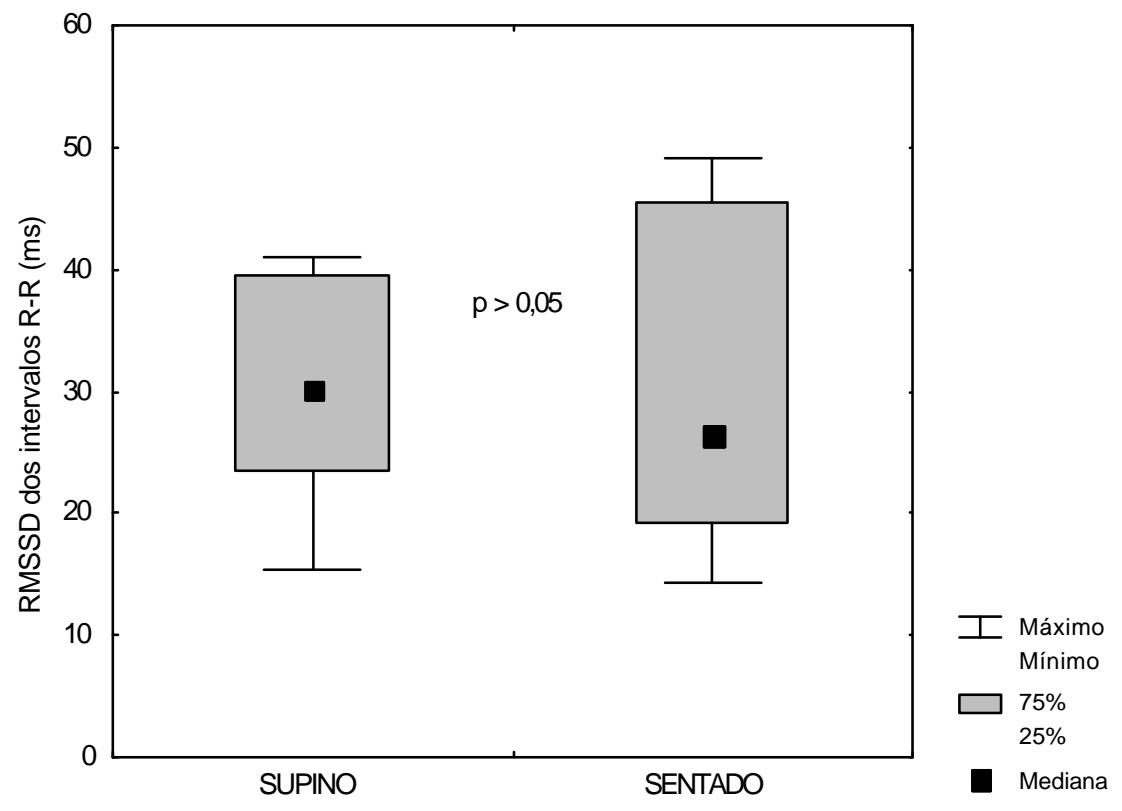

Figura 8. RMSSD dos intervalos RR em milissegundos (ms) observados no período de 900 segundos, em repouso nas posições supina e sentada dos voluntários estudados $(\mathrm{N}=12)$. Nível de significância á=0,05.

\subsection{Freqüência cardíaca durante o teste de exercício físico dinâmico em degraus descontínuos}

Verifica-se na figura 9 que no início do exercício físico, independente do nível de potência aplicada, ocorre uma elevação rápida dos valores absolutos da FC. Após este período inicial, verifica-se uma redução da FC que se apresenta diferente em cada potência realizada pelos voluntários. Em potências baixas a FC tende a uma estabilização e dbserva-se uma maior VFC. Observa-se ainda que com os incrementos de potências, ocorre uma elevação lenta da FC. Entretanto, em níveis de potências submáximas é difícil identificar visualmente o momento da inclinação do conjunto de dados da FC. Portanto, faz-se necessária a utilização de uma abordagem matemática e estatística que permita melhor quantificação a respeito da mudança do comportamento da resposta da FC. 


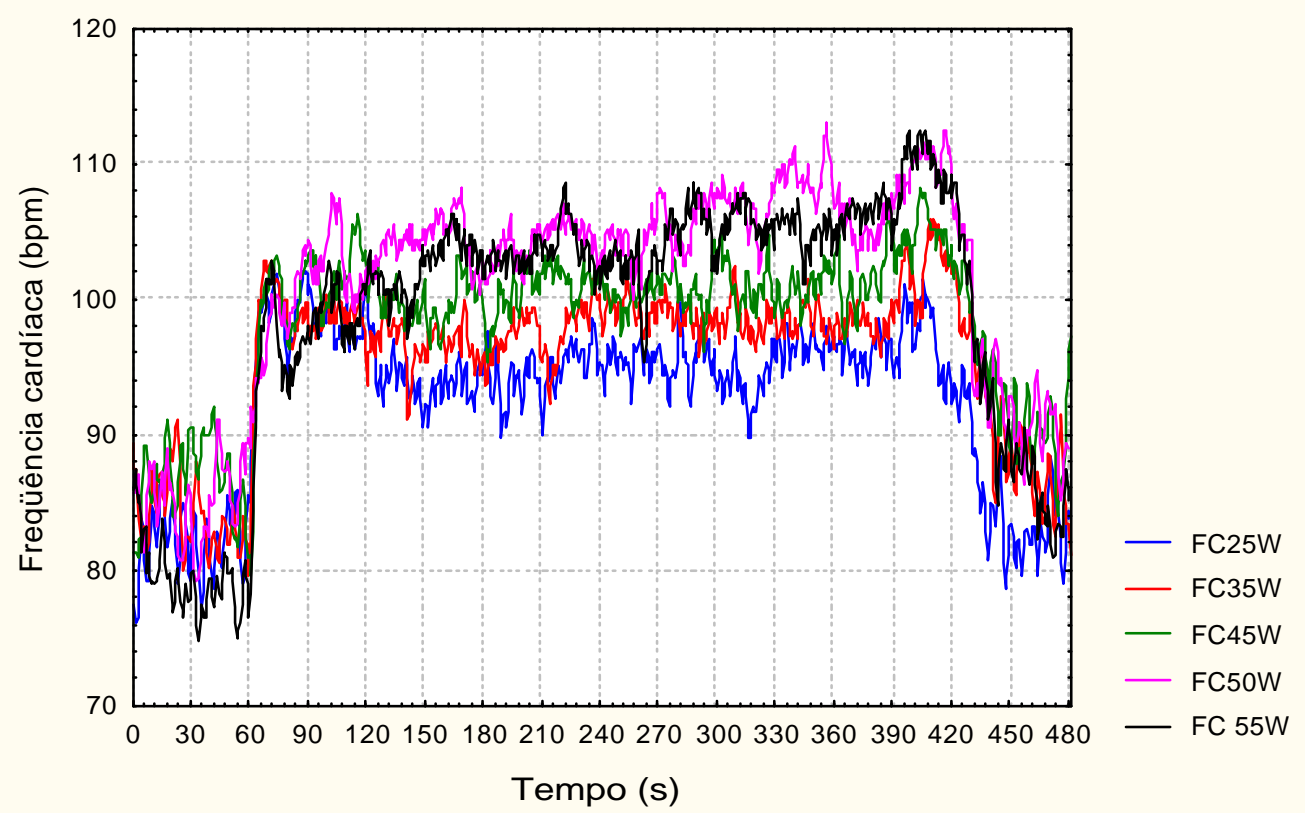

Figura 9. Resposta da frequiência cardíaca captada batimento a batimento, em tempo real, em repouso $(60 \mathrm{~s})$, durante $(420 \mathrm{~s})$ do teste de exercício físico dinâmico descontínuo, com potências progressivas de 25, 35, 45, 50, $55 \mathrm{~W}$ e em recuperação (60s), obtida em um dos voluntários estudados (CRB).

\subsubsection{Variação da freqüência cardíaca e do tempo no início do exercício físico}

$\mathrm{Na}$ figura 10 verifica-se que os valores das variações da FC (bpm) e do tempo no início do exercício físico (entre 0 e 20s) não apresentaram diferenças estatisticamente significantes $(\mathrm{p}>0,05)$ quando comparadas as potências aplicadas. 


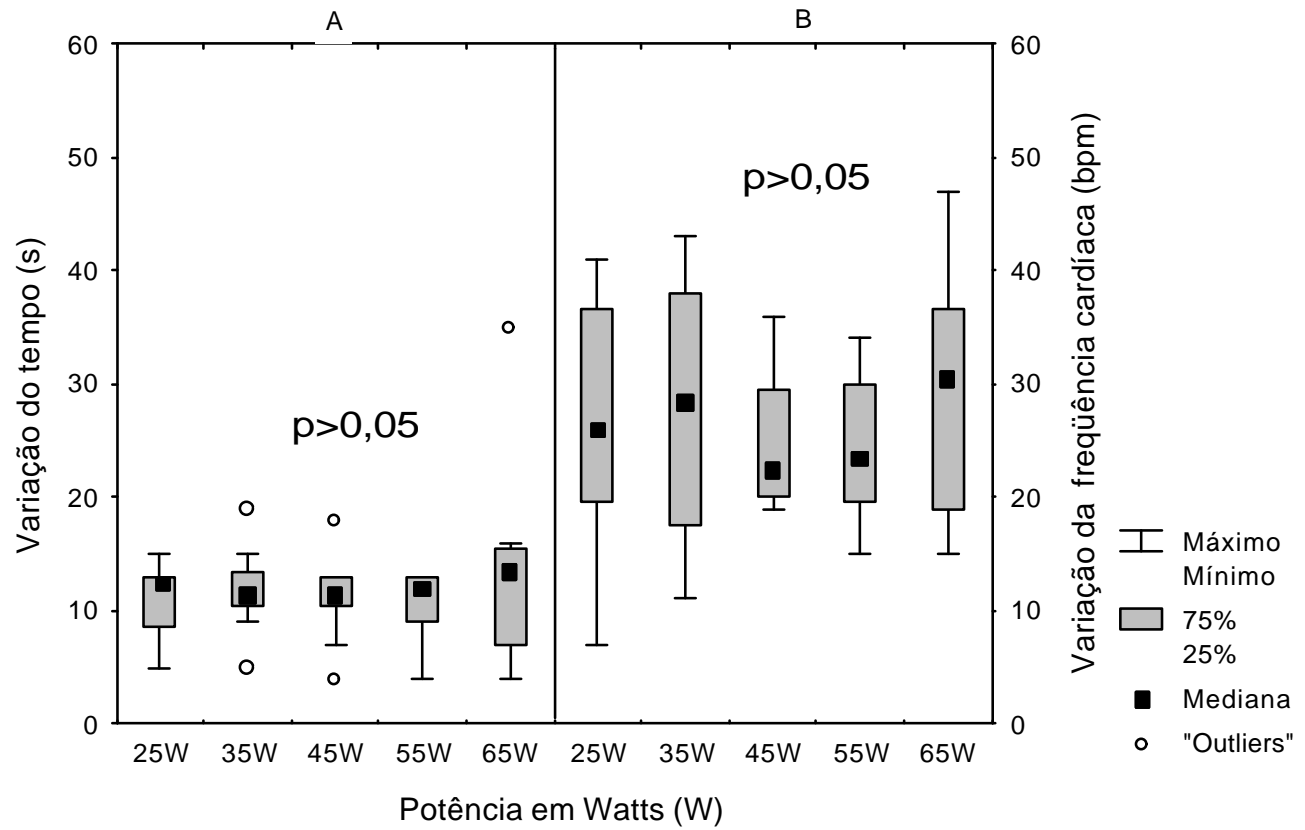

Figura 10. Em A, tempo em segundos (s) de elevação da FC nas potências de 25, 35, 45, 55 e 65 Watts (W) durante os TEFDD-D e em B, variação da freqüência cardíaca, em batimentos por minuto (bpm) $(\mathrm{N}=12)$. Nível de significância á $=0,05$.

\subsection{Análise da variabilidade da freqüência cardíaca durante o teste de exercício}

\section{físico dinâmico em degraus descontínuos.}

A VFC foi analisada por meio do índice temporal RMSSD dos IRR em ms durante o período de 120 a 420 s do registro, durante os testes de exercício físico dinâmico descontínuo realizados pelos 12 voluntários.

Na figura 11 estão apresentados os índices de RMSSD dos IRR (ms) obtidos da condição de repouso sentada e nos níveis de potência de 25, 35, 45, 55 e 65 Watts (W). Verifica-se que houve diferenças estatisticamente significantes em relação à posição de repouso sentada e as potências de $55 \mathrm{~W}$ e $65 \mathrm{~W}(\mathrm{p}<0,05)$, entre a potência de $25 \mathrm{~W}$ em relação às potências de $55 \mathrm{~W}$ e $65 \mathrm{~W}(\mathrm{p}<0,05)$ e entre a potência de $35 \mathrm{~W}$ em relação às potências de $55 \mathrm{~W}$ e $65 \mathrm{~W}(\mathrm{p}<0,05)$. 


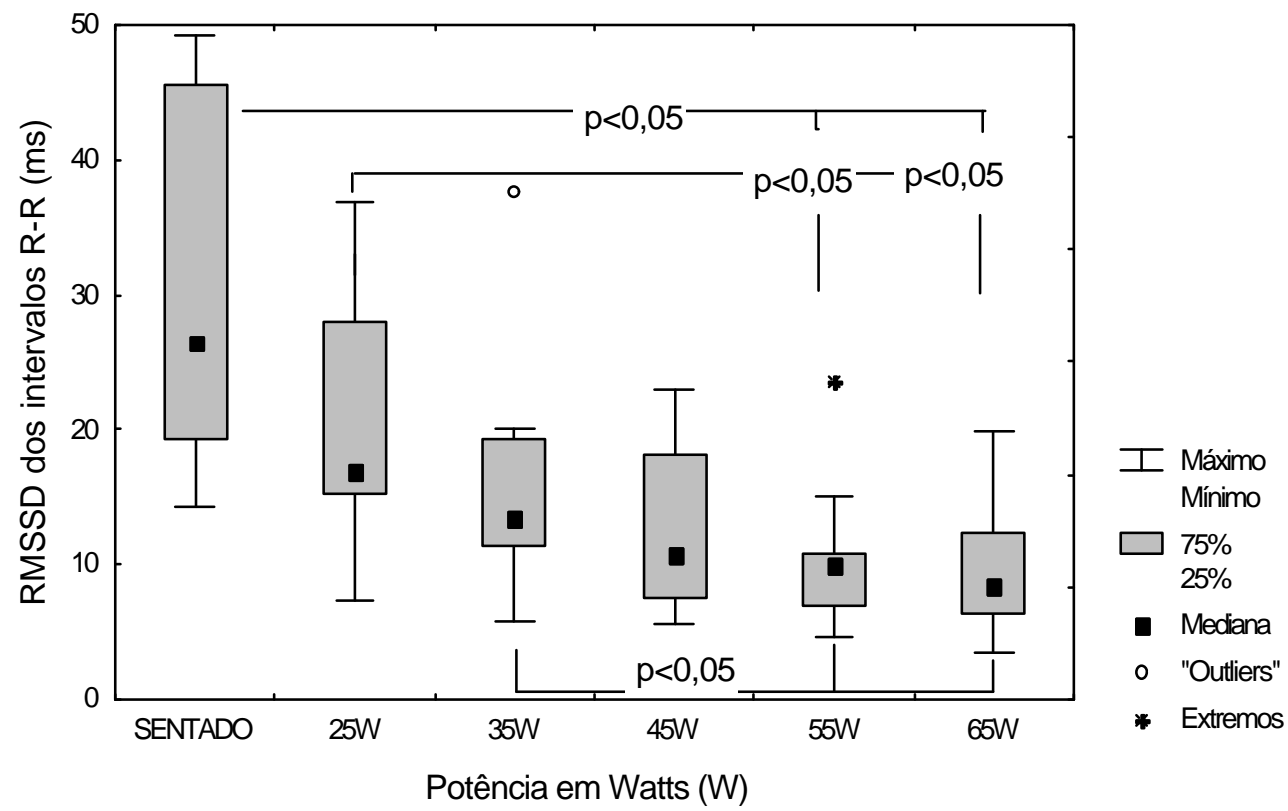

Figura 11. Valores dos índices RMSSD a partir dos intervalos RR em milissegundos na condição de repouso sentado e nas potências de $25,35,45,55$ e 65 Watts (W), no intervalo de 120 a 420s, durante o TEFDD-D. Nível de significância á=0,05 (N=12).

\subsection{Nível de potência em Watts atingida no teste de avaliação da capacidade}

\section{funcional e no nível do limiar de anaerobiose}

A figura 12 apresenta os valores de potência (W) pico atingidas no teste de avaliação da capacidade funcional (TEFDC-D) em relação às atingidas no LA determinado a partir dos modelos SMP e ARIMA. Nota-se que houve diferenças estatisticamente significantes entre a potência pico do TEFDC-D e as do LA obtidas pelos 2 métodos $(\mathrm{p}<0,05)$. Quanto à variabilidade dos dados (distância entre o $1^{\underline{0}}$ e $3^{\stackrel{0}{ }}$ quartis) esta foi maior nas potências obtidas pela metodologia ARIMA. 


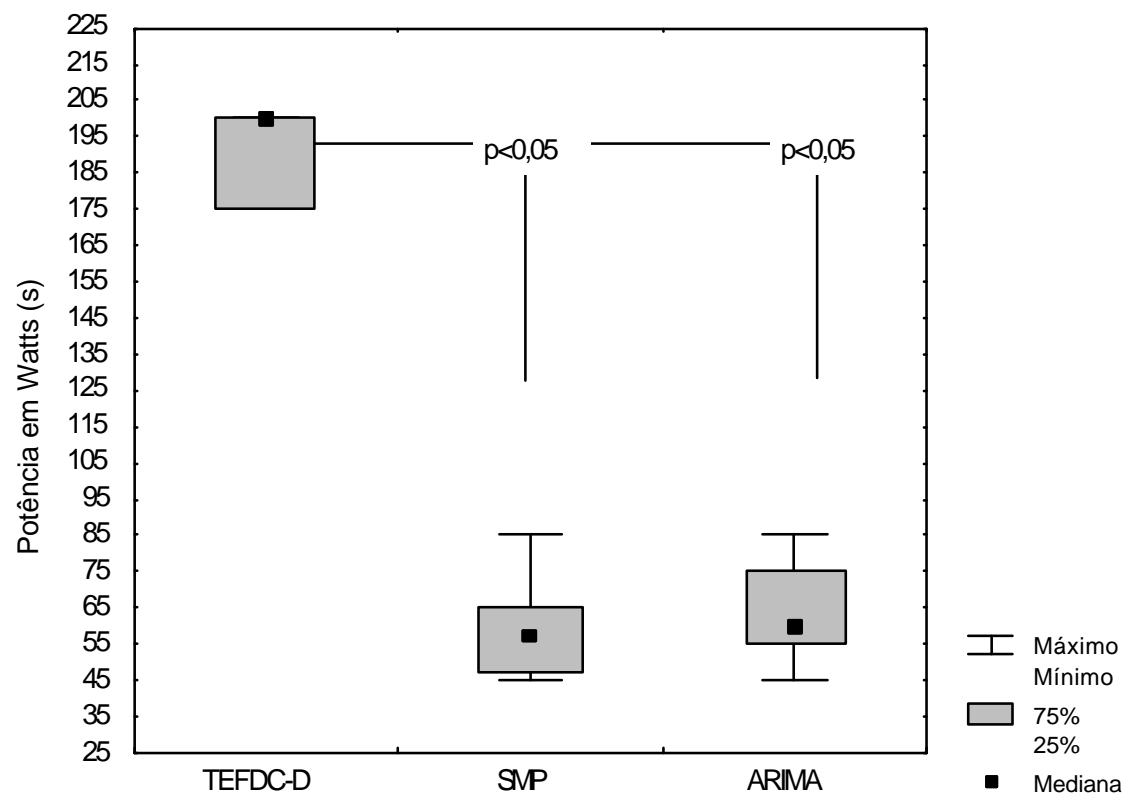

Figura 12. Relação entre os valores de potência pico atingida durante o TEFDC-D e as potências atingidas no LA pelas análise dos modelos semiparamétrico (SMP) e ARIMA durante os TEFDD-D ( $\mathrm{N}=12)$. Nível de significância á=0,05.

4.5.1. Percentual de potência ao nível do limiar de anaerobiose determinado pelas análises dos modelos semiparamétrico e do modelo ARIMA em relação à potência pico atingida no teste de exercício físico dinâmico contínuo

Na figura 13 observa-se que o valor percentual de potência ao nível do LA obtido pela metodologia ARIMA foi similar ao obtido pelo modelo SMP $(\mathrm{p}>0,05)$. 


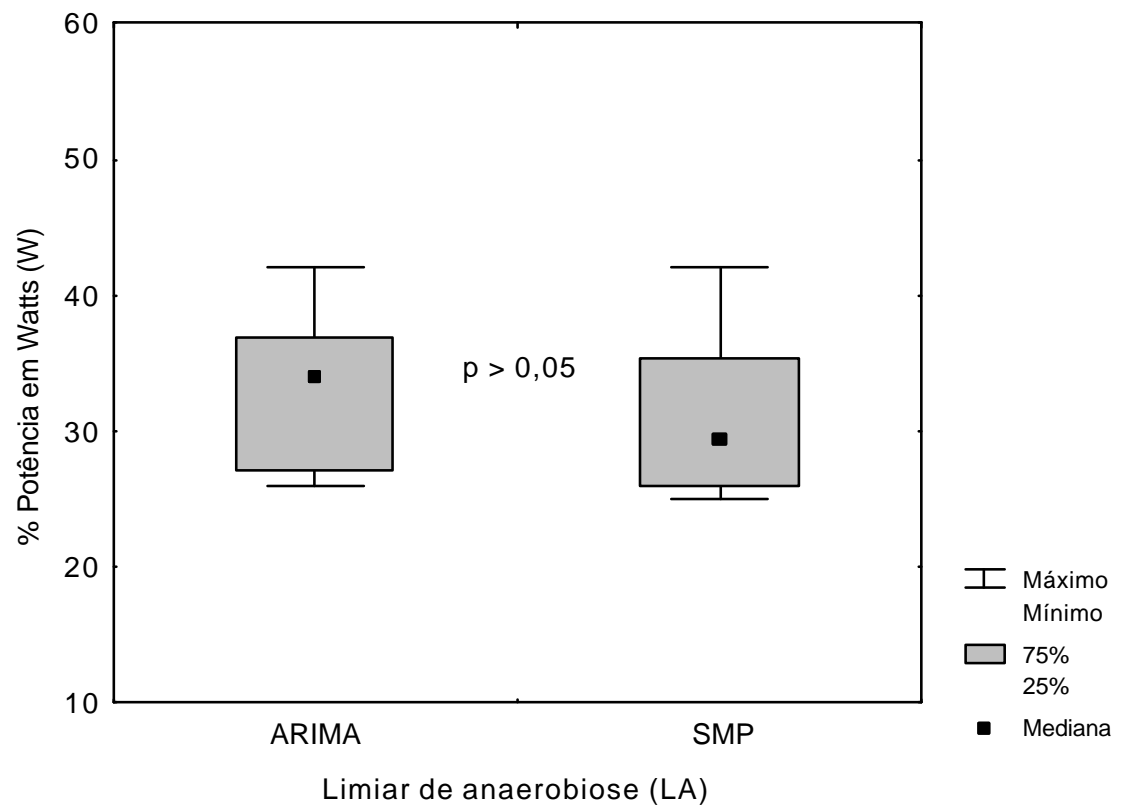

Figura 13. Dados percentuais (\%) de potência de exercício físico no limiar de anaerobiose (LA) pelas metodologias semiparamétrica (SP) e ARIMA em relação à potência pico atingida durante o teste de exercício físico dinâmico contínuo (N=12). Nível de significância á=0,05.

\subsubsection{Freqüência cardíaca pico atingida durante o teste de avaliação da capacidade funcional e no nível do limiar de anaerobiose}

$\mathrm{Na}$ figura 14 observa-se os valores de FC pico (bpm) atingidos no TEFDC-D relacionado aos atingidos no nível do LA determinado a partir dos modelos semiparamétrico e ARIMA. Nota-se que houve diferenças estatisticamente significantes entre a FC pico do TEFDC-D e as do TEFDD-D no nível do LA obtido pelos 2 métodos $(\mathrm{p}<0,05)$. 


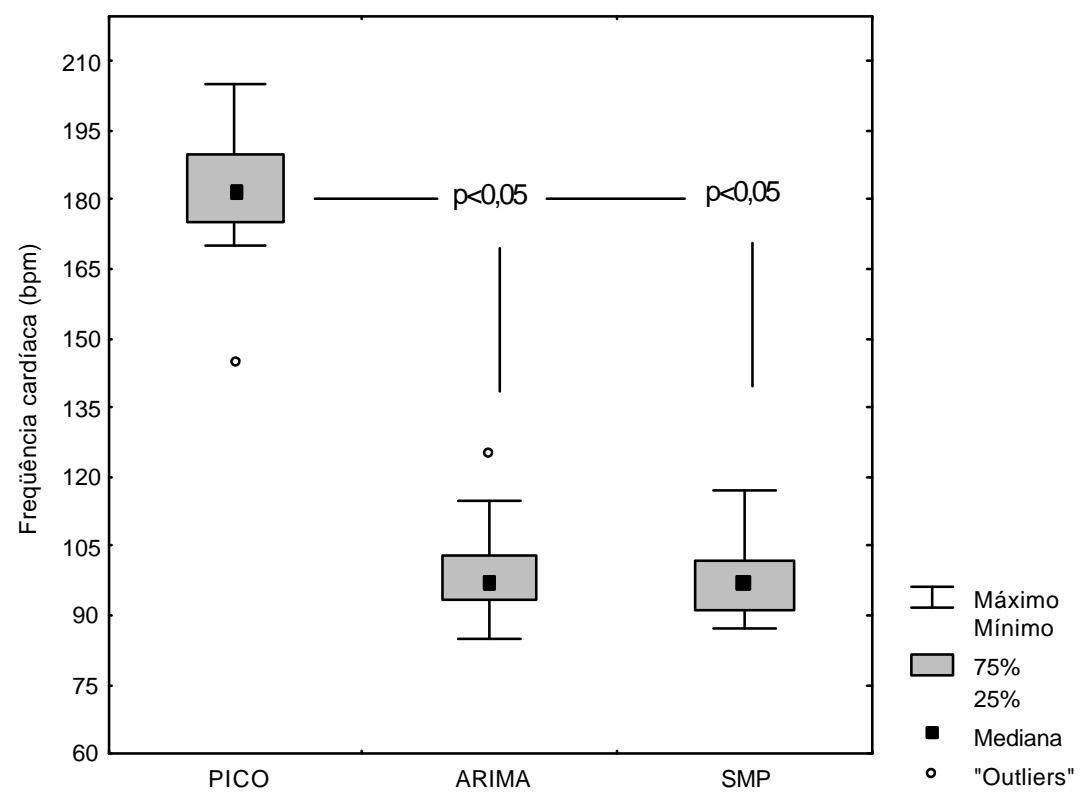

Figura 14. Relação entre os valores de FC pico atingidas durante o TEFDC-D e as pico atingidas pelas metodologias SMP e ARIMA durante os TEFDD-D $(\mathrm{N}=12)$. Nível de significância á=0,05.

4.5.3. Percentual da frequiência cardíaca ao nível do limiar de anaerobiose determinado pelas análises dos modelos SMP e ARIMA em relação à potência pico atingida no teste de exercício físico dinâmico contínuo

Na figura 15 observa-se que o valor percentual de FC atingida no LA determinada pela metodologia ARIMA foi similar ao obtido pelo modelo SMP $(\mathrm{p}>0,05)$. 


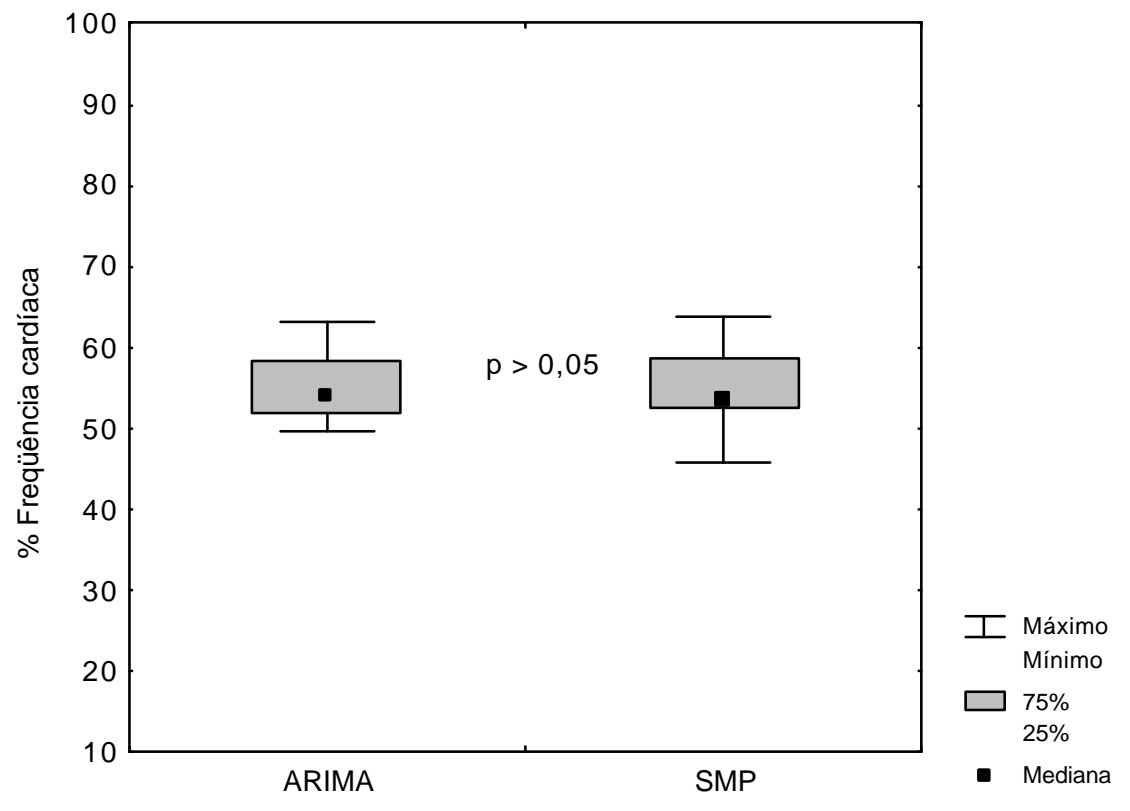

Figura 15. Dados percentuais de freqüência cardíaca em batimentos por minuto (bpm) obtidos no nível do LA, determinado pelas metodologias ARIMA e SMP, em relação à potência pico atingida durante o teste de esforço físico dinâmico contínuo. Nível de significância á=0,05 (N=12).

\subsubsection{Análise da variabilidade da freqüência cardíaca durante o TEFDD-D nos níveis de potências em que foi determinado o limiar de anaerobiose}

Verifica-se na figura 16 que os índices de RMSSD dos IRR em ms, obtidos no nível de potência em que foi determinado o LA pelas duas metodologias de análise, modelo ARIMA e modelo SMP, não apresentaram diferenças estatisticamente significantes $(\mathrm{p}<0,05)$, assim como entre aos valores de RMSSD na potência de $55 \mathrm{~W}$, onde observou-se diferenças estatisticamente significantes em relação ao repouso e demais potências testadas (verificar figura 11) . 


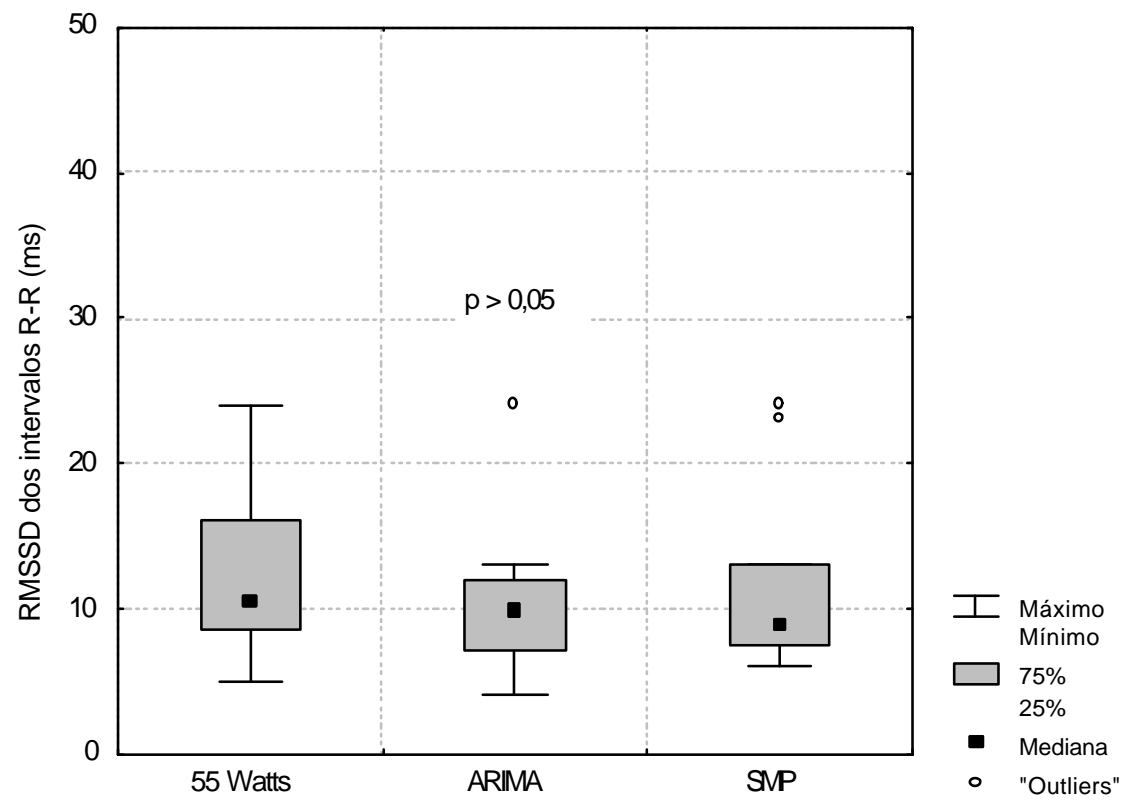

Figura 16: Valores de RMSSD dos intervalos R-R em ms durante o TEFDD-D na potência de $55 \mathrm{~W}$ e nos níveis de potências em que foi determinado o LA pelas metodologias: ARIMA e SMP $(\mathrm{N}=12)$. Nível de significância $\alpha=$ $0,05(\mathrm{~N}=12)$.

\subsection{Análises de correlação}

4.6.1. Análise de correlação entre as potências atingidas no momento do limiar de anaerobiose determinado pelos modelos semiparamétrico e ARIMA durante o TEFDD-D

A associação entre as potências atingidas no momento do LA determinado pelos modelos semiparamétrico e ARIMA está representada na figura 17. Verifica-se que apesar dos dados apresentarem-se dispersos em torno da bissetriz, a correlação obtida $\left(r_{s}=0,72\right)$ foi estatisticamente significante $(p<0,05)$. 


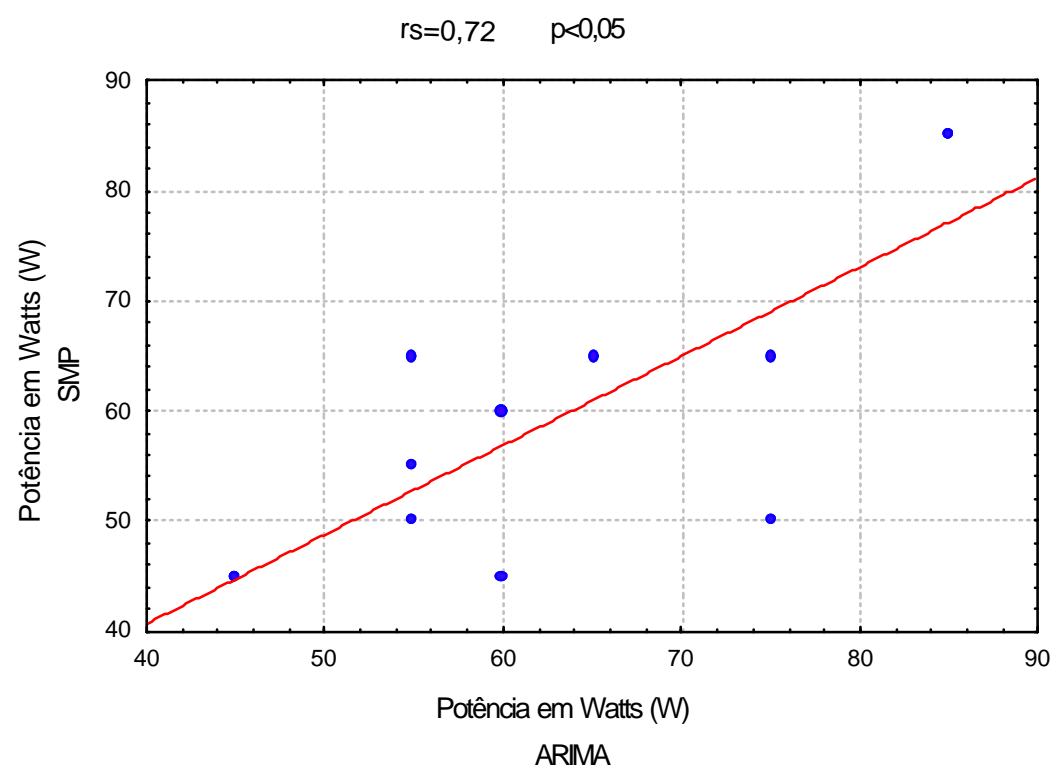

Figura 17. Associação entre os valores de potência em Watts (W) atingidas no momento do LA determinado pelos modelos SMP e ARIMA $(\mathrm{N}=12)$. Nível de significância $\alpha=0,05$.

\subsubsection{Análise de correlação entre valores de frequiência cardíaca no nível de potência do limiar de anaerobiose, durante o TEFDD-D}

Verifica-se na figura 18 a associação entre os valores de FC atingida no nível de potência do LA pelos modelos SMP e ARIMA. Observa-se correlação estatisticamente significante $\left(r_{s}=0,87\right.$ e $\left.p<0,05\right)$, apesar de uma certa dispersão dos dados em torno da bissetriz. 


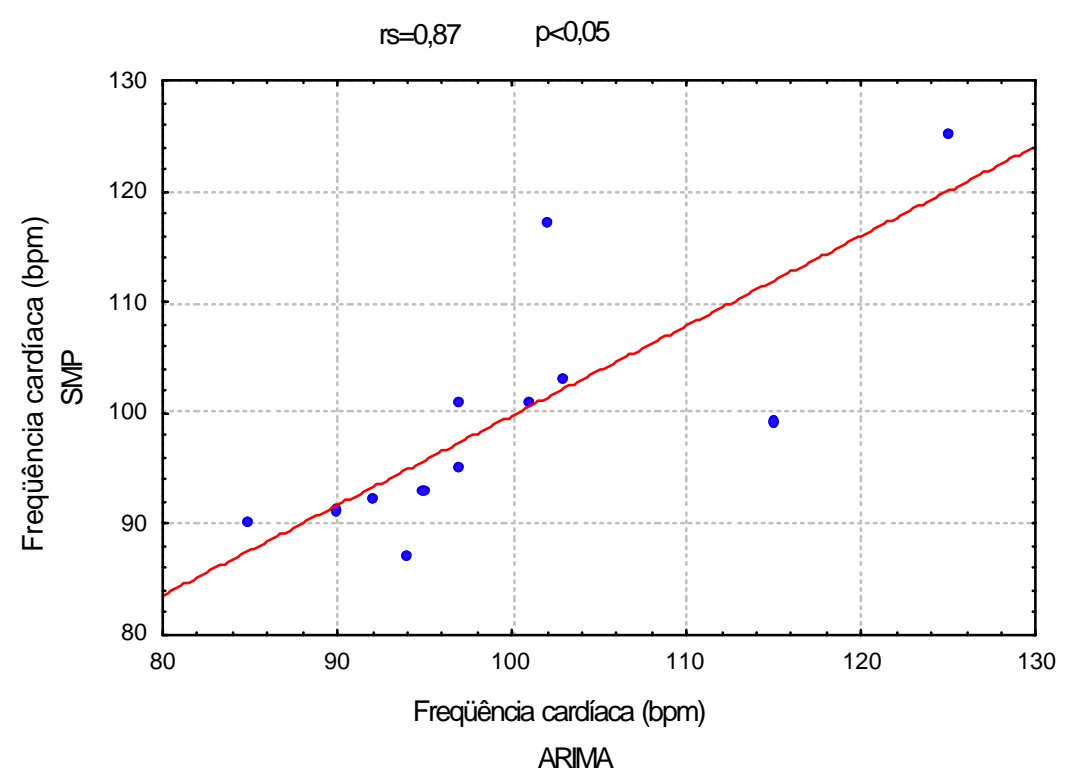

Figura 18. Associação entre os valores de frequiência cardíaca obtidas no nível de potência em que foi determinado o LA pelos modelos SMP e ARIMA durante o TEFDD-D (N=12). Nível de significância $\alpha=0,05$.

\subsubsection{Análise de correlação entre valores do índice de variabilidade da freqüência cardíaca (RMSSD) no nível de potência do limiar de anaerobiose, durante o TEFDD-D.}

Verifica-se na figura 19 que a associação dos valores dos índices de RMSSD dos IRR (ms) no nível de potência do LA, obtido pelos modelos SMP e ARIMA, estão dispersos em torno da bissetriz apresentando correlação estatisticamente significante $(r s=0,82$ e $p<0,05)$ 


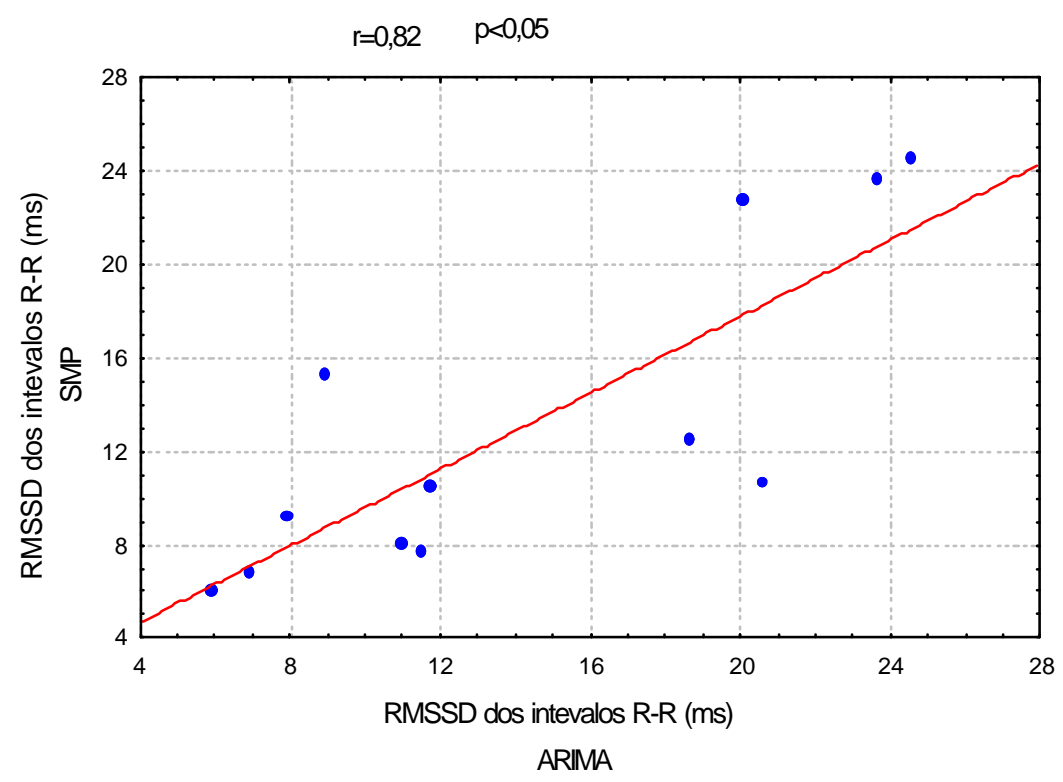

Figura 19. Associação entre os valores dos índices RMSSD dos IRR em ms, durante o TEFDD-D, no nível de potência em que ocorreu o LA, pelos dois modelos SMP e ARIMA (N=12). Nível de significância $\alpha=0,05$. 


\section{DISCUSSÃO}

\subsection{Características antropométricas}

Esta bem estabelecido na literatura que as respostas fisiológicas ao exercício físico são dependentes de vários fatores, tais como característica antropométrica, estilo de vida, condição de saúde, entre outros (GALLO et al. 1987). Dessa forma, a presente investigação foi conduzida considerando-se a padronização dos fatores acima referidos como um controle de qualidade obrigatório, no sentido de caracterizar a amostra e controlar suas variações em função das interferências nas respostas fisiológicas. Tal procedimento reduz a variabilidade das variáveis estudadas permitindo maior confiabilidade na interpretação fisiológica. Assim, incluiu-se no presente estudo um grupo de voluntários bastante homogêneo apresentando diferenças de pequena magnitude em relação as características antropométricas, estilo de vida e condições de saúde. Portanto estabeleceu-se para este estudo que somente seriam incluídos voluntários que se encontrassem na faixa etária de 40 a 50 anos. Assim, podemos inferir que as diferenças de idade dos mesmos, observadas na presente investigação não foram significativas a ponto de interferir nas respostas fisiológicas. 


\subsection{Análise da resposta da frequiência cardíaca e de sua variabilidade}

\subsubsection{Na condição de repouso nas posições supina e sentada}

Em decorrência do envelhecimento, ocorrem alterações na modulação do sistema nervoso autônomo e do sistema cardiovascular como mudanças estruturais e funcionais na sensibilidade dos tecidos, no sistema de condução cardíaca, nos vasos sanguíneos e barorreceptores, aumento da rigidez miocárdica e diminuição no enchimento ventricular, que vão refletir na hemodinâmica do sistema cardiovascular (WALSH, 1987; BLAIR et al.,1988). Além destes fatores o nível de condicionamento físico também exerce grande influência na FC de repouso (SHANON, CARLEY \& BENSON, 1987; RICKLI et al., 1997; TULPPO et al.;1998).

A modulação autonômica da FC é em parte responsável pela variabilidade da mesma, e em voluntários saudáveis, na condição de repouso, tanto o simpático como o parassimpático estão tonicamente ativos, com efeito predominantemente vagal. A estimulação dos nervos parassimpáticos está associada à diminuição dos valores de FC enquanto a estimulação do simpático está associada ao aumento destes (MACIEL, 1986; MALIANI, 1995).

A análise da VFC constitui um meio relativamente simples e nãoinvasivo na investigação da modulação autonômica do coração (SAUL et al., 1990; LOMBARDI et al., 1987; LOMBARDI et al., 1992; BIGGER et al., 1995; PERSSON, 1997 - apud CATAI 1999). Vários estudos têm mostrado que a variabilidade da FC diminui com a idade (TULPPO et al.,1998; MARÃES,1999, CATAI et al, 2002).em ambos os sexos (GREGOIRE et al.1996; DAVY et al.1998).

Tem sido referido na literatura uma faixa de normalidade para valores de RMSSD em torno de $27 \pm 12 \mathrm{~ms}$ considerando-se a faixa etária entre $40-50$ 
anos. Os valores absolutos encontrados no presente trabalho, isto é, $32 \pm 19$ ms são maiores do que os acima referidos (Task Force, 1996).

Durante a mudança postural, seja ela ativa ou passiva, ocorrem variações no tônus vago-simpático, envolvendo a ativação das vias eferentes simpáticas e diminuição da modulação da eferência parassimpática para o sistema cardiovascular. A mudança postural desencadeia importantes modificações das variáveis cardiovasculares por desvios hidrostáticos e respostas reflexas adaptativas, causadas por deslocamento de sangue das extremidades superiores para as inferiores, diminuição do volume sistólico e aumento da FC na manutenção do débito cardíaco e da pressão arterial sistêmica, ativação dos mecanorreceptores arteriais e cardiopulmonares e integração de informações periféricas e centrais. (BEVEGARD, et al., 1967; LINDQVIST, 1990; McARDLE, KATCH \& KATCH, 1996; JESUS, 1996).

No presente estudo, os menores valores médios absolutos de frequiência cardíaca, encontrados na posição supina em relação à posição sentada, podem estar relacionados a fatores ligados à modulação vago-simpática pela mudança postural. Entretanto, pela análise dos índices temporais (RMSSD) não foram observadas alterações na variabilidade da FC relacionadas à mudança postural. Esses resultados são concordantes com os observados por MARÃES (1999) em estudo com homens jovens e de meia-idade, saudáveis e com padrão ativo de vida e por RIBEIRO (2001b), em estudo com mulheres jovens e pós menopausa. Isso nos mostra que em determinadas condições fisiológicas podem ocorrer mudanças na modulação vago-simpática, sem que ocorram modificações no padrão da VFC analisada no domínio do tempo. 


\subsection{Padrão de resposta da freqüência cardíaca durante o esforço físico}

\subsubsection{Análise descritiva e no domínio do tempo}

O exercício físico promove um marcado aumento em algumas variáveis hemodinâmicas como o débito cardíaco, a pressão arterial sistêmica, a freqüência cardíaca a fim de atender uma elevada demanda metabólica que se instala nestas condições (McARDLE, KATCH \& KATCH, 1996). A modificação dessas variáveis ocorre por processos de ajustes do controle autonômico, como mudanças no tônus vago-simpático sobre o sistema cardiovascular (MACIEL et al.,1986; SILVA, 1988; BALDISSERA, 1992; CATAI, 1992 e 1999; CHACON-MIKAHIL et al., 1998).

Além da condição em repouso, o estudo da resposta da FC durante o exercício físico é bem discutido por vários autores, em que o eferente parassimpático contribui em maior escala no exercício de baixa intensidade, e com o aumento da potência de esforço físico ocorre predominância da atuação do componente simpático no nó sino atrial (LINNARSON, 1974; MACIEL, 1986; SILVA, et al. 1988; CATAI, 1992; GALLO JR et al., 1995).

No que se refere à resposta da FC ao exercício dinâmico, em indivíduos saudáveis, LINNARSON (1974) analisou esta variável mais detalhadamente no decurso do tempo subdividindo-a em 3 fases, a saber: uma primeira, com duração de 10 a 15 s a partir do início do exercício onde se nota uma elevação rápida da FC, atribuída à retirada do tônus vagal atuante no coração, sendo observada independente da potência de esforço físico aplicada; uma segunda elevação bem lenta da FC que se instala entre os 60 e $90 \mathrm{~s}$ do exercício, e finalmente, uma terceira, também de instalação lenta, de curso quase linear que se propaga por todo o período de execução do exercício que é dependente da intensidade de esforço físico e que tem sido atribuída à estimulação simpática no coração. No presente estudo, pela análise visual das curvas de resposta da FC ao exercício físico dinâmico, 
os dados foram similares ao referido na literatura em todas as potências realizadas pelos voluntárias estudados (LINNARSON, 1974; MACIEL et al.1986, SILVA, 1988).

$\mathrm{Na}$ presente investigação, ao ser analisado o instante $\mathrm{t}$ (s) em que a elevação rápida da FC atingiu seu maior valor no início do exercício, observamos que este tempo não é fixo, ou seja, a retirada vagal se estabelece de forma individual, com tempos distintos e em função do nível de potência do esforço físico. Verificamos que este tempo em mediana foi de 12,$5 ; 11,5 ; 11,5 ; 12$ e $13,5 \mathrm{~s}$ para as potências de $25,35,45,55$ e 65 Watts, respectivamente. Esses resultados são semelhantes aos obtidos por SILVA (1988) e RIBEIRO (2001) que encontraram constantes de tempo de $13 \mathrm{~s}$ para a potência de 25 Watts, sendo que para as demais potências os resultados não foram semelhantes.

As variações da FC ( $\Delta$ de FC) no início do exercício, observada para os voluntários de meia idade foram semelhantes em todas as potências estudadas. Nossos dados são discordantes aos encontrados por CATAI (1999) que trabalhou com homens de meia-idade sedentários e observou menor magnitude de resposta rápida da FC. As diferenças encontradas podem ser atribuídas à metodologia utilizada, quanto à captação, registro e análise dos dados de FC, pois vários dos trabalhos referidos (MACIEL et al., 1986; GALLO Jr. et al. 1988; CATAI, 1999), utilizaram-se de dados médios de FC em um intervalo de tempo pré estabelecido, enquanto nossos dados foram captados em tempo real, ou seja, batimento a batimento, em função do tempo. Outro fator que pode ter interferido é o nível de aptidão física do grupo de voluntários estudados.

Vários trabalhos estabeleceram que a inibição vagal, em cada nível de exercício dinâmico, completa-se ao redor do primeiro minuto, sendo que o tônus vagal residual é inversamente proporcional à potência de esforço aplicada. Assim, se por um lado a contribuição do subsistema parassimpático é maior no exercício dinâmico de menor potência, por outro lado, a participação simpática começa a prevalecer com o aumento da intensidade da mesma (ROBINSON et al., 1966; SMITH, 1974; MACIEL, 1983; SILVA, 1988). A magnitude de cada um desses dois 
subsistemas eferentes é variável de indivíduo para indivíduo, sendo que o grau de contribuição simpática e parassimpática é dependente, entre outros fatores, do nível de treinamento físico individual (MACIEL, 1983; SILVA et al. 1988).

Outros estudos (SEAL et al., 1994; DAVY et al., 1998) referem que com o aumento da idade ocorre uma redução na modulação vagal sobre o coração, fato esse que parece limitar a capacidade da retirada vagal atenuando a taquicardia rápida em resposta a certos estímulos fisiológicos.

\subsection{Análise da resposta da freqüência cardíaca e de sua variabilidade durante o exercício físico dinâmico}

Têm sido proposto na literatura metodologias de análise da resposta da FC ao exercício físico, considerando as oscilações periódicas do ritmo cardíaco (KAMATH et al. 1991; RIMOLDI et al., 1992; MARÃES, 1999). Quando analisamos as respostas da freqüência cardíaca em termos de sua variabilidade, torna-se evidente que a representação de batimento a batimento, por incorporar os componentes de variação rápida da $\mathrm{FC}$, permite uma melhor caracterização da resposta fisiológica, razão pela qual, utilizamos valores dos parâmetros obtidos desta forma.

Quando analisamos os índices de RMSSD dos intervalos RR em milisegundos que reflete a VFC, na condição de repouso em relação ao exercício físico observamos que tais índices diminuem com o aumento progressivo das potências e tornam-se mais evidentes e estatisticamente significantes em níveis de potências mais elevados, 55 e 65 Watts, para este grupo. Esta diminuição da VFC pode ser explicada por uma menor participação do sistema parassimpático no controle da FC e com predomínio da ativação do sistema nervoso simpático(MARÃES, 1999; RIBEIRO, 2001a).

Uma grande variedade de índices são usados na avaliação da VFC no domínio do tempo, de acordo com a revisão da literatura. Entretanto, ainda não está 
bem definido se algum deles é superior aos outros para melhor quantificar a VFC (ANTILA, 1979; LONGO et al.,1995; TASK FORCE , 1996).

A seleção do índice RMSSD neste estudo está baseada na sensibilidade deste índice por usar a diferença dos quadrados (ANTILA, 1979). A escolha pelo uso do período de 6 minutos de registro para avaliação da VFC, ou seja, avaliação de um curto período, está baseada no fato de que esse intervalo de tempo permite uma estabilização da variabilidade dos IRR (ms). Muitos estudos, dentro desta área do conhecimento, têm dado suporte a esse tipo de avaliação (TASK FORCE, 1996; MARKS et al., 1999; SINNREICH, et al., 1998).

A observação e a análise da VFC no domínio do tempo por meio da monitorização por eletrocardiograma, em registros de curto período, podem oferecer importantes informações prognósticas adicionais, além daquelas que provêm de uma avaliação tradicional dos fatores de risco. A análise da VFC, no domínio do tempo, pode ser considerada, portanto, um método relativamente simples, não invasivo e sensível na identificação de alterações da modulação autonômica sobre o nódulo sinusal, do que aquelas que consideram apenas valores médios de FC e IRR, tanto em condições de repouso e durante o exercício físico, bem como em estímulos fisiológicos (ALONSO, et al., 1998; MARÃES, 1999; RIBEIRO, 2001).

\subsection{Aplicação de modelos matemáticos e estatísticos na análise do padrão de resposta da freqüência cardíaca em exercício físico na determinação do limiar de anaerobiose.}

O limiar de anaerobiose é um importante parâmetro indicador da capacidade física dos indivíduos, que corresponde ao momento no qual o metabolismo anaeróbio passa a ter importância na produção de energia, com acúmulo simultâneo de lactato nos músculos e conseqüentemente ácido láctico na circulação sanguínea (BARROS NETO, 1996; CHACON-MIKAHIL et al., 1998; WASSERMAN et al., 1999). 
Dentre os diferentes métodos utilizados para a detecção do LA, dois mais comumente usados são: um invasivo por meio da dosagem do lactato sangüíneo (COYLE et al. 1983; WELTMAN et al., 1990; FOSTER et al., 1999) e o outro nãoinvasivo, por meio da mudança do padrão das respostas das curvas ventilatórias durante o exercício físico dinâmico contínuo e incremental (WASSERMAN, 1990; WASSERMAN et al.,1999; CHACON-MIKAHIL, 1998 a,b; CATAI, 1999; FORTI, 1999).

Entretanto, neste estudo, optamos em utilizar outras abordagens de análise matemática e estatística para estimar o LA. Sendo duas baseadas na resposta da FC por meio da aplicação do modelo ARIMA (RIBEIRO et al., 1998; MARÃES, 1999; GARCEZ et al., 2000) e do modelo matemático e estatístico semiparamétrico (SAKABE et al. 2002) e outra baseada na VFC utilizando-se os índices de RMSSD dos IRR como descrito anteriormente (RIBEIRO, 2001a,b).

\subsubsection{Modelos autorregressivos-integrados-médias móveis (ARIMA) na detecção do limiar de anaerobiose.}

BOX-JENKINS (1970) propôs o uso de modelos de séries temporais autorregressivo integrado de médias móveis para analisar a mudança de padrões de respostas, onde ocorrem a perda de suas estacionariedades. Neste contexto, o conjunto de dados da FC em exercício pode ser visto como uma série temporal, que consiste, fundamentalmente de um conjunto de observações de uma variável $y$, tomada em intervalos de tempo igualmente espaçados.

Existem dois aspectos a serem considerados no estudo de séries temporais: análise e modelagem. O objetivo da análise é resumir as propriedades da série e caracterizar a sua forma. Isto pode ser feito tanto no domínio do tempo como no domínio da freqüência. No domínio do tempo focalizamos a relação entre observações em diferentes pontos do tempo; Por outro lado, no domínio da frequiência estudamos os movimentos cíclicos. As duas formas de análise são complementares e competitivas, ou seja, a mesma informação é processada de 
diferentes maneiras. O objetivo da modelagem é fazer previsões, a respeito do comportamento da variável estudada.

Uma série temporal pode ser considerada como um processo estocástico; para que ela seja analisada, é necessário decompô-la em uma parte fixa (estrutura) e uma parte aleatória (erro) (MORETTIN \& TOLOI, 1985; MORETTIN \& TOLOI 1986). Para saber se a estrutura está contendo toda, ou a maior parte da variabilidade da série observando as características do resíduo. O resíduo é usado para se estimar o erro, uma vez que é impossível obtermos o erro real, que é um componente teórico. Nestas circunstâncias, é necessário que o resíduo tenha média zero, variância constante, e que não seja auto-correlacionado. Satisfeitas estas condições, o resíduo será denominado de ruído branco (ANDERSON, 1976; JENKIS, 1979).

A estrutura da série só poderá ser feita se esta for estacionária, i.e., a série deverá flutuar ao redor de um nível fixo $\mu$; quando isto não acontece, pode-se tornar a série estacionária através de diferenças. A parte estrutural da série será construída relacionando-se as observações passadas, modelo autorregressivo, e quando há necessidade de muitos parâmetros, também usam-se modelos médias móveis, que contêm os valores dos erros passados. Esse novo modelo é denominado ARMA (autorregressivo-médias móveis), e no caso de série não estacionária, onde é necessário fazer diferenças, o modelo é denominado ARIMA (autorregressivointegrado-médias móveis) (MORETTI \& TOLOI, 1985; TAGARIS et al., 1997).

Foi, portanto, usando-se a metodologia de BOX JENKINS (1970), com o ajuste dos modelos autorregressivos-integrados-médias móveis (ARIMA) que se determinou o momento em que o conjunto de dados de FC apresentava tendência (inclinação), caracterizando um incremento lento da FC; incremento este, que segundo estudos conduzidos em condições de bloqueio beta-adrenérgico, é causado por estimulação do sistema nervoso simpático (MACIEL et al., 1986; GALLO Jr. et al., 1987; GALLO Jr. et al., 1995).

No que se refere ao presente estudo os voluntários de meia-idade saudáveis atingiram o LA em valores medianos de potência de 60 Watts e de FC de 
100 bpm, esses achados são semelhantes aos obtidos em nosso Laboratório de Fisioterapia Cardiovascular - Núcleo de Pesquisa em Exercício Físico da UFSCar, em estudos preliminares, usando a mesma metodologia (ARIMA). Assim, MARÃES (1999) estudando 21 voluntários saudáveis jovens e de meia-idade, usando protocolo de esforço físico dinâmico descontínuo com potências progressivas, com duração de 12 minutos em cada potência, com o mesmo tipo de cicloergômetro (bicicleta de frenagem eletromagnética), observou inclinação da resposta da FC em valores medianos de potências de 75 e 60 Watts para voluntários jovens e de meia-idade, respectivamente.

\subsubsection{Modelo matemático e estatístico semiparamétrico na detecção do limiar de anaerobiose.}

O modelo semiparamétrico é um modelo matemático e estatístico, composto por componentes paramétricos e não paramétricos aplicados à mesma variável, o qual propõe a separação dos componentes da série em questão, no caso a FC obtida durante o exercício físico, em duas partes, sendo que a primeira apresenta tendências lineares em relação ao modelo ajustado com configuração paramétrica correspondente aos resíduos da série e a segunda parte contém os elementos da primeira parte com configuração não paramétrica. A tendência à inclinação dos valores de FC é dada por uma análise de variância e teste t de Student com nível de significância de á $=0,05$.

O componente paramétrico admite que os resíduos da série têm distribuição normal e aplicando-se teste de Durbin-Watson, este não indica autocorrelação significante entre os resíduos. O componente não paramétrico se ajusta aos componentes cíclicos da série e para isso é preciso uma ortogonalização em relação aos elementos do componente paramétrico, do período de 180 a 420 segundos a ser analisado, onde se observa maior estabilidade da série. O modelo, através de uma análise de dados apresenta inclinação positiva ou negativa, ou seja, o quanto esta inclinação difere de zero, com p<0,05. 
Pelo método semiparamétrico, o LA foi caracterizado durante o exercício, como o momento em que a FC apresentou uma inclinação positiva e estatisticamente significante. Por esta análise os voluntários atingiram o LA em valores medianos no nível de potência de 57 Watts e de FC de 96 bpm. Estes resultados são concordantes com os resultados encontrados por SAKABE et al. (2002) que referem uma mudança do padrão de resposta da FC analisada pelo modelo semiparamétrico, que por sua vez coincide com a diminuição mais acentuada da variabilidade da FC. Nos trabalhos de MARÃES (1999) e RIBEIRO (2001b) é citado que a perda da estabilidade da FC e a diminuição da VFC se devem ao predomínio da atividade simpática sobre o nódulo sinusal.

Quando analisamos os RMSSD dos intervalos RR milisegundos nas potências realizadas em comum pelo grupo estudado verificamos em 55 Watts os menores valores deste índice. Outro aspecto importante a ser considerado é que os índices de RMSSD dos intervalos RR em milisegundos na potência correspondente ao LA determinado pelos modelos SMP e ARIMA e ao RMSSD dos intervalos RR milisegundos na potência de 55 Watts foram similares, mostrando que tanto pelo modelo ARIMA como pelo modelo SMP, os valores RMSSD dos intervalos RR milisegundos foram correspondentes aos valores observados no nível da potência de 55 Watts. 


\section{CONCLUSÕES}

A partir dos resultados obtidos no presente estudo, considerando-se a metodologia de análise empregada, podemos chegar as seguintes conclusões:

A análise da variabilidade da frequiência cardíaca, a partir do índice de RMSSD dos intervalos RR em milisegundos foi sensível na identificação de alterações da modulação autonômica sobre o nódulo sinusal.

O aumento da freqüência cardíaca com concomitante redução da variabilidade da frequiência cardíaca, associado ao incremento de potências sugere uma menor participação da atuação vagal e predomínio da atividade simpática sobre o coração.

Os resultados obtidos pelas três metodologias de análise foram similares e apresentaram correlação estatisticamente significante, mostrando que são adequadas para detectar o ponto de mudança de inclinação da resposta da freqüência cardíaca concomitante ao achatamento da variabilidade da frequiência cardíaca como indicativo do limiar de anaerobiose. 


\section{REFERÊNCIAS BIBLIOGRÁFICAS}

ALONSO, D.O.; FORJAZ, C.L.M.; REZENDE, L.O.; BRAGA, A.M.F.W.; BARRETO, A.C.P.; NEGRÃO, C.E.; RONDON, M.U.P.B. Comportamento da frequiência cardíaca e da sua variabilidade durante as diferentes fases do exercício físico progressivo máximo. Arq Bras Cardiol, v. 71, n. 6, p. 787-792, 1998.

ANDERSON, T.W. Times series analysis and forecasting the Box \& Jenkins approach. London \& Boston, Butterworths, 1976.

ANTILA, K. Quantitative characterization of heart rate during exercise. Scand J Clin Lab Invest, v. 153, p. 13-58, 1979 (Suppl).

ASTRAND, P.O. \& RODAHL, K. Tratado de Fisiologia do Exercício. 2 ed. Ed Interamericana, 1980.

BALDISSERA, V. Estudo da variabilidade do limiar de anaerobiose e frequiência cardíaca de indivíduos sedentários e atletas durante exercício físico dinâmico em cicloergômetro, utilizando-se rampas corrigidas. 1992. Tese (Doutorado), Faculdade de Medicina de Ribeirão Preto, Universidade de São Paulo, Ribeirão Preto.

BARROS NETO, T.L. Fisiologia do exercício aplicada ao sistema cardiovascular. Rev Soc Cardiol Estado de São Paulo, v. 6, n. 1, p. 6-10, 1996.

BELCASTRO, A.N.; BONEN, A. Lactic acid removal rates during controlled and uncontrolled exercise. J Appl Physiol, v. 39, n. 6, p. 932-936, 1975.

BEVERGARD, G.E.P.; SHEPHERD, J.T. Regulation of the circulation during exercise in man. Physiology Rev, v. 47, p. 178-208, 1967.

BIGGER, J.T.; FLEISS, J.L.; STEINMAN, R.C.; ROLNITZKY, L.M.; SCHNEIDER, W.J.; STEIN, P.K. RR variability in healthy, middle-aged persons compared with patients with chronic coronary heart disease or recent acute myocardial infarction. Circulation, v. 91, n. 7, p. 1936-1943, 1995. 
BOX-JENKINS. Times series analisys. Holden-Day. San Francisco, USA. 1 ed, 1970.

BLAIR, S.N.; PAINTER, P.; PATE, R.R.; SMITH, L.K.; TAYLOR, C.B. Resource Manual for Guidelines for Exercise Testing and Prescription. Am Coll Sports Medicine. Philadelphia, Lea \& Febiger, 1988.

BUNC, V.; HOFMANN, P.; LEITNER, H.; GAISL, G. Verification of the heart rate threshold. Eur J Appl Physiol, v. 70, p. 263-269, 1995.

BROOKS, G.A., Current concepts in lactate exchange. Med Sci Sports Exerc, v. 23, n. 8, p 895-906, 1991.

CAIOZZO, V.J.; DAVIS, J.A.; ELLIS, J.F.A comparasion of gas exchange indices used to detect the anaerobic threshold. J Appl Physiol, v. 53, n. 5, p. 1184- 1189, 1982.

CATAI, A.M. Adaptações cárdio-respiratórias em atletas: estudo em diferentes fases do treinamento físico. 1992. Tese (Mestrado), Faculdade de Educação Física Universidade Estadual de Campinas, Campinas.

CATAI, A. M.; CHACON-MIKAHIL, M.P.T.; MARTINELLI, F.S.; FORTI, V.A.M.; GOLFETTI, R.; MARTINS, L.E.B.; SZRAJER, J.S.; WANDERLEY, J.S.; GALLO Jr., L. Cardiorespiratory responses during dynamic exercise using different ergometers in sedentary young men. In: THE FASEB JOURNAL, 1996. Resumos..., The Faseb Journal, 1996, v. 10, p. A375.

CATAI, A.M. Estudo da capacidade aeróbia e da variabilidade da freqüência em homens jovens e de meia-idade submetidos a treinamento físico aeróbio. 1999. 301p. Tese (Doutorado em Ciências) - Instituto de Biologia, Universidade Estadual de Campinas, Campinas.

CATAI, A.M.; CHACON-MIKAHIL, M.P.T.; MARTINELLI, F.S.; FORTI, V.A.M.; GOLFETTI, R.; MARTINS, L.E.B.; LIMA-FILHO, E.C.; SILVA, E.; GALLO Jr., L. Aerobic capacity and heart rate variability responses in young and middle-age men. In: 47 ANNUAL MEETING, Indianapolis. Resumos, Indianapolis: Medicine \& Science Sports \& Exercise, v. 32, n. 5, p.64, 2000 (Supl.).

CATAI, A. M.; CHACON-MIKAHIL, M. P.; MARTINELLI, F. S.; FORTI, V. A.; SILVA, E.; GOLFETTI, R.; MARTINS, L. E.; SZRAJER, J. S.; WANDERLEY, J. S.; LIMA-FILHO, E. C.; MILAN, L. A.; MARIN-NETO, J. A.; MACIEL, B. C.; GALLO-JUNIOR, L. Effects of aerobic exercise training on heart rate variability during wakefulness and sleep and cardiorespiratory responses of young and middleaged healthy men. Braz J Med Biol Res, v. 35, 6; 741-52 
CHACON-MIKAHIL, M.P.T. Estudo da variabilidade da freqüência cardíaca nos domínios do tempo e da frequiência antes e após o treinamento físico aeróbio em homens de meia-idade. 1998. 196 p. Tese (Doutorado em Ciências) - Instituto de Biologia, Universidade Estadual de Campinas, Campinas.

CHACON-MIKAHIL, M.P.T., FORTI, V.A.M.; CATAI, A.M.; SZRAJER, J.S.; GOLFETTI, R.; MARTINS, L.E.B.; LIMA-FILHO, E.C.; WANDERLEY, J.S.; MARIN-NETO, J.A.; MACIEL, B.C.; GALLO JR, L. Cardiorespiratory adaptations induced by aerobic training in middle-aged men: the importance of a decrease in sympathetic stimulation for the contribution of dynamic exercise tachycardia. Braz J Med Biol Res, v. 31, n. 5, p. 705-712, 1998.

COYLE, E.F.; MARTIN, W.H.; EHSANI, A.A.; HAGBERG, J.M.; BLOOMFIELD, S.A.; SINACORE, D.R.; HOLLOSZY, J.O. Blood lactate threshold in some welltrained ischemic heart disease patients. J Appl Physiol, v. 54, n. 1, p. 18-23, 1983.

CUMMING, G.R. \& CARR, W. Hemodynamic response to exercise after betaadrenergic and parasympathetic blockade. Can J Physiol Pharmacol, v. 45, n. 5, p. 813-819, 1967.

DAVIS, J.A.; FRANK, M.H., WHIPP, B.J. WASSERMAN, K. Anaerobic threshold alterations caused by endurance training in middle-aged men. J Appl Physiol, v. 46, n. 6, p. 1039-1046, 1979.

DAVIS, J.A. Anaerobic threshold: review of the concept and directions for future research. Med Sci Sports Exerc, v. 17, n. 1, p. 6-18, 1985.

DAVY, K.P.; De SOUZA, C.A.; JONES, P.P.; SEALS, D.R. Elevated heart rate variability in physically active young and older adult women. Clin Sci (Lond), v. 94, n. 6, p. 579-584, 1998.

EKBLON, B.; ASTRAND, P.O.; STENBERG, J.; WALLSTROM, B. Effect of training on circulatory response to exercise. J Appl Physiol, v. 24, n.4, p. 518-528, 1968.

FARREL, P.A.; WILMORE, J.H.; COYLE, E.F.; BILLING, J.E.; COSTILL, D.L. Plasma lactate accumulation and distance running performance. Med Sci Sports Exercise, n. 11, p. 338-344, 1979.

FORTI, V.A.M. Influência do treinamento físico aeróbio sobre as respostas cardiovasculares e respiratórias em mulheres na menopausa com e sem terapia de reposição hormonal. 1999. 213p. Tese (Doutorado em Educação Física) Universidade Estadual de Campinas, Campinas. 
FOSTER, C.; FITZGERALD, D.J.; SPATZ, P. Stability of the blood lactate-heart rate relationship in competitive athletes. Med Sci Sports Exerc, v. 31, n. 4, p. 578$582,1999$.

GALLO Jr, L.; MACIEL, B.C; MARIN-NETO, J.A.; MARTINS, L.E.B.; LIMAFILHO, E.C.; MANÇO, J.C. The use of isometric exercise as a means of evaluating the parasympatic contribuition to the tachycardia induced by dinamic exercise in normal man. Pflügers Arch., v. 412, p. 128-132, 1988.

GALLO Jr., L.; MORELO FILHO, J.; MACIEL, B.C.; MARIN NETO, J.A.; MARTINS, L.E.B.; LIMA FILHO, E.C. Functional evaluation of sympathetic and parasympathetic system in Chagas' disease using dynamic exercise. Cardiovasc Res, v. 21, p. 922-927, 1987.

GALLO Jr, L.; MACIEL, B.C.; MARIN-NETO, J.A.; MARTINS, L.E.B. Ajustes cardiovasculares ao exercício físico. Efeitos do treinamento aeróbio. Medicina, v. 23, n. 2, p. 101-106, 1990.

GALLO JR., L.; MACIEL, B.C; MARIN-NETO, J.A.; MARTINS, L.E.B.; LIMAFILHO, E.C.; GOLFETTI, R., CHACON, M.P.T.; FORTI, V.A.M. Control of heart rate during exercise in health and disease. Braz J Med Biol, v. 28, p. 1179-1184, 1995.

GALLO Jr, L.; MACIEL, B.C.; MARTINS, L.E.B.; LIMA FILHO, E.C.; GOLFETTI, R. Quando o coração bate mais forte. Ciência Hoje, v. 21, p. 40-47, 1996.

GARCEZ, A. R. R.; VISCONDE, F. J.; ZAITUNE, M. P. A.; MARÃES, V. R. F. S.; MOURA, M. S. A.; VERZOLA, R. M. M.; GOUVÊA, E. C.; OLIVEIRA, L.; GALLO JÚNIOR, L.; SILVA, E.; CATAI, A. M. Avaliação do limiar de anaerobiose em homens com fatores de risco para doença da artéria coronária e com doença da artéria coronária. Revista da Sociedade de Cardiologia do Estado de São Paulo, São Paulo, v.11, n.3, p. 5-17, maio/junho, 2001.

GOUVÊA, E.C.; CATAI, A.M.; SILVA, E.; OLIVEIRA, L.; MILAN, L.A.; GALLO Jr, L.; BARCELOS, S.R.; TREVELIN, L.C. Implementação e incorporação dos módulos de análise de dados e emissão de relatórios ao sistema computacional de eletrocardiografia de esforço. In: VI CONGRESSO DE INICIAÇÃO CIENTÍFICA DA UFSCar, São Carlos, 1998. Anais..., São Carlos, UFSCar, 1998.

GREEN, H.J.; HUGHSON, R.L.; ORR, G.W.; RANNEY, D.A. Anaerobic threshold, blood lactate and muscle metabolites in progressive exercise. J Appl Physiol, v. 54, n. 4, p. 1032-1038, 1983. 
GREGOIRE, J.; TUCK, S.; YAMAMOTO, Y.; HUGHSON, R.L. Heart rate variability at rest and exercise: influence of age, gender, and physical training. Can J Appl Physiol, v. 21, n. 6, p. 455-470, 1996.

JESUS, P.C. Considerações metodológicas e caracterização de procedimentos implicados nas análises temporal e espectral da variabilidade da frequiência cardíaca, para avaliação clínica do controle autonômico do coração. 1996. Tese (Mestrado), Faculdade de Ciências da Saúde, Universidade de Brasília, Brasília.

JENKINS, G.M. Practical experiences with modeling and forescasting time series. Jersey, Channel Islands, GLP Publications, 1979.

JORFELDT, JUHLIN-DANNFELT, A.; KARLSSON, J. Lactate release in relation to tissue lactate in human skeletal muscle during exercise. J Appl Physiol, v. 44, n. 3, p. 350-352, 1978.

KAMATH, M.V.; FALLEN, E.L.; MCKELVIE, R. Effects of steady state exercise on the power spectrum of heart rate variability. Med Sci Sports Exerc, v. 23, n. 4, p. 428-434, 1991.

KINDERMANN, W.; SIMON, G.; KEUL, J. The significance of the aerobicanaerobic transition for the determination of work load intensities during endurance training. Eur J Appl Physiol Occup Physiol, v. 42, n. 1, p. 25-34, 1979.

KNUTTGEN, H.G. Oxygen debt, lactate, pyruvate, and excess lactate after muscular work. J Appl Physiol, v. 17, n. 4, p. 639-644, 1962.

KOIKE, A.A.; WEILER-RAVELL, D.; MCKENZIE, D.K.; ZANCONATO, S.; WASSERMAN, K. Evidence that the metabolic acidosis threshold is anaerobic threshold. J Appl Physiol, v. 68, n. 8, p. 2521-2526, 1990.

LINNARSON, D. Dynamics of pulmonary gas exchange and the heart rate changes at start and end of exercise. Acta Physiol Scand, (Suppl. 415): 1974.

LINDQVIST, A. Noninvasive methods to study autonomic nervous control of circulation. Acta Physiol Scand, v. 588, p. 1-107, 1990 (Suppl.).

LONGO, A.; DANIEL, F.; CORREIA, M.J. Variabilidade da frequiência cardíaca. Rev Port Cardiol, v. 14, n. 3, p. 241-262, 1995.

LOMBARDI, F.; SANDRONE, G.; PERNPRUNER, S.; SALA, R.; GARIMOLDI, M; CERUTTI, S.; BASELLI, G.; PAGANI, M.; MALLIANI, A. Heart rate variability as a index of sympathovagal interaction after acute myocardial infarction. Am J Cardiol, v. 60, p. 1239-1245, 1987. 
LOMBARDI, F.; SANDRONE, G.; MORTARA, A.; ROVERE, M.T., COLOMBO, E.; GUZZETTI, S.; MALLIANI; A. Circadian variation of spectral indices of heart rate variability after myocardial infarction. Am Heart J, v. 123, p. 1521-1528, 1992.

MACIEL, B.C. Contribuição de mecanismos autonômicos nas modificações da frequiência cardíaca induzidas pelo treinamento físico. 1983. Tese (Doutorado em Clínica Médica), Faculdade de Medicina - Universidade São Paulo, Ribeirão Preto.

MACIEL, B.C.; GALLO Jr., L.; MARIN-NETO, J.A.; MARTINS, L.E.B. Autonomic nervous control of the heart rate during dynamic exercise in normal men. Clin Sci (Lond), v. 71, n. 4, p. 457-460, 1986.

MALLIANI, A. Association of heart rate variability components with physiological regulatory mechanism. In: MALIK, M, CAMM, A. J. Heart rate variability. Futura Publishing Company, Inc., Armonk, New York, Chapter 14: 173-188, 1995.

MARÃES, V.R.F.S.; CATAI, A.M.; OLIVEIRA, L.; MOURA, M.S.A.; TREVELIN, L.C.; GALLO, Jr., L.; SILVA, E.; Study of variability of instantaneous heart rate for the detection of anaerobic threshold. In: L CONGRESSO NAZIONALE DELLA SOCIETÀ ITALIANA DI ANATOMIA, 1996, Catania. Resumos..., Roma: Archivio Italiano di Anatomia ed Embriologia, 1996, v. 101, p. 123-123.

MARÃES, V.R.F.S. Estudo da variabilidade da frequiência cardíaca durante exercício físico dinâmico em voluntários sadios. 1999. 225p. Tese (Mestrado em Biologia Funcional e Molecular) - Instituto de Biologia, Universidade Estadual de Campinas, Campinas.

MARÃES, V.R.F.S.; SILVA, E.; CATAI, A.M.; GALLO Jr, L.; OLIVEIRA, L.; RIBEIRO, T.F., MOURA, M.S.A.; CANOTILHO, M.M. Avaliação da capacidade física de pacientes com doença pulmonar obstrutiva crônica de grau leve e moderado a partir da resposta da frequiência cardíaca: relato de caso. Rev Soc Cardiol Estado de São Paulo, v. 10, n. 3, p. 6-15, 2000 (Suppl A).

MARKS, B.L.; LIGHTFOOT, J.T. Reproducibility of resting heart rate variability with short sampling periods. Can J Appl Physiol, v. 24, p. 337-48, 1999.

McARDLE, W.D.; KATCH, F.I.; KATCH, V.L. Exercise physiology. Energy, nutrition and human performance. 4 ed. Williams \& Wilkins, Baltimore, 1996.

MITCHELL, J.H.; KAUFMAN, M.P.; IWAMOTO, G.A. The exercise pressure reflex: its cardiovascular effects, afferent mechanisms, and central pathways. Annu. Rev Physiol, p. 229-242, 1983. 
MORETTIN, P.A.; TOLOI, C.M. Previsão de Séries Temporais. Atual editora, São Paulo, 1985.

MORETTIN, P.A.; TOLOI, C.M. Métodos Quantitativos: Séries Temporais. Atual editora, São Paulo, 1986.

OLIVEIRA, L.; MILAN, L.A; CATAI, A.M; GALLO Jr, L.; SILVA, E. Modelo Semiparamétrico de análise do comportamento da frequiência cardíaca. In: XVII REUNIÃO DA FEDERAÇÃO DE SOCIEDADES DE BIOLOGIA EXPERIMENTAL - FeSBE, 2002, Salvador. Anais..., Salvador, 2002, p. 59.

PERSSON, P.B. Spectrum analysis cardiovascular time series. Am J Physiol, v. 273 (Regulatory Integrative Comp. Physiol. 42): R 1201-R 1210, 1997.

RIBEIRO, T.F., GOMES, V.R.; MOURA, M.S.A.; MARÃES, V.R.F.S.; CATAI, A.M.; OLIVEIRA, L.; TRAVELIN, L.C.; GALLO Jr., L.; SILVA, E. Estudo do limiar de anaerobiose em mulheres sedentárias durante o esforço físico dinâmico. In: XVII REUNIÃO DA FEDERAÇÃO DE SOCIEDADES DE BIOLOGIA EXPERIMENTAL - FeSBE, 1998, Caxambu. Anais..., Caxambu, 1998, p. 258.

RIBEIRO, T. F. Investigação da variabilidade da freqüência cardíaca de mulheres nos períodos manhã e noite. Rev Bras Fisiot, v. 5, n. 2, p. 65-71, 2001 a.

RIBEIRO, T. F. 2001. Avaliação da modulação autonômica da atividade eferente do coração pela variabilidade da freqüência cardíaca em mulheres sedentárias. 2001b. Tese (Mestrado em Fisioterapia), Universidade Federal de São Carlos, São Carlos.

RICKLIN, H.; MACCARTER, D.J.; MAIRE, R.; AMANN, F.W.; CANDIANS, R. Age and sex related changes in heart rate to ventilation coupling: implications for rate adaptative pacemaker algorithms. Pace, v. 20, p. 104-111, 1997.

RIMOLDI, O.; FURLAN, R.; PAGANI, M.R.; PIAZZA, S.; GUAZZI, M.; PAGANI, M.; MALLIANI, A. Analysis of neural mechanisms accompanying different intensities of dynamic exercise. Chest, v. 101, p. 226S-230S, (5 Suppl), 1992.

ROBISON, B.F.; EPSTEIN, S.E.; BEISER, G.D.; BRAUNWALD, E. Control of heart rate by the autonomic nervous system. Studies in man on the interrelation between baroreceptor mechanisms and exercise. Circ Res, v. 19, p. 400-411, 1966.

SAKABE, D.I.; FERREIRA, V.; RIBEIRO, T.F.; AZEVEDO, G.D.; MILAN, L.A.; CATAI, A.M.; OLIVEIRA, L.; GALLO Jr, L.; SILVA DE SÁ, M.F.; SILVA, E. Use of a semi-parametric model for the analysis of heart rate variability (HRV) in order to determine the anaerobic threshold of middle-aged men and postmenopausal 
women receiving or not hormonal replacement therapy. In: $13^{\mathrm{TH}}$ ANNUAL MEETING OF THE NORTH AMERICAN MENOPAUSE SOCIETY (NAMS), 2002, Chicago. Anais..., Chicago, p. 94, 2002.

SAUL, J.P. Beat-to-beat variations of HR reflect modulation of cardiac autonomic outflow. NIPS, v. 5, p. 32-37, 1990.

SEALS, D.R.; TAYLOR, J.A.; NG, A.V; ESLER, M.D. Exercise and aging: autonomic control of the circulation. Med Sci Sports Exercise, v. 26, p. 568-576, 1994.

SEALS, D.R.; VICTOR, R.G. Regulation of muscle sympathetic nerve activity during exercise in humans. Exerc Sport Sci Rev, v. 19, p. 313-349, 1991.

SHANON, D.C.; CARLEY, D.W.; BENSON, H. Aging modulation of heart rate. Am J Physiol, v. 253, p. H874-H877, 1987

SILVA, E. Modelos matemáticos da resposta da freqüência cardíaca ao exercício físico dinâmico em indivíduos normais. 1988. Tese (Mestrado em Ciências Biológicas) - Instituto de Biologia, Universidade Estadual de Campinas, Campinas.

SILVA, E.; GALLO Jr, L.; MARTINS, L.E.B.; MACIEL, B.C.; MARIN-NETO, J.A. Inadequacy of second order models to characterize the heart rate response induced by dynamic exercise. Braz J Med Biol Res, v. 21, p.61-63, 1988.

SILVA, E.; CATAI, A.M. Ficha de Avaliação, Depto de Fisioterapia e Terapia Ocupacional da UFSCar, São Carlos, SP, 1991, 6 páginas, formulário.

SILVA, E. Influência do exercício isométrico nas respostas da freqüência cardíaca e eletromiográficas no homem 1998. Dissertação (Doutorado) - Instituto de Biologia da Universidade Estadual de Campinas, Campinas.

SILVA, E.; CATAI, A.M.;TREVELIN, L.C.; GUIMARÃES, J.O.; SILVA Jr. L.P.; SILVA, L.M.P; OLIVEIRA, L.; MILAN, L.A.; MARTINS, L.E.B.; GALLO Jr., L. Design of a computerized system to evaluate the cardiac function during dynamic exercise. Phys Med Biol, v. 33a, p. 409, 1994.

SIMON, J.; YOUNG, J.L.; GUTIN, B.; BLOOD, D.K.; CASE, R.B. Lactate accumulation relative to the anaerobic and respiratory compensation threshold. $\mathbf{J}$ Appl Physiol, v. 54, n. 1, p. 13-17. 1983.

SMITH, O.A. Reflex and central mechanics involved in the control of the heart and circulation. Ann Rev Physiol, v. 36, p. 93, 1974. 
SINNREICH, R.; KARK, J.D.; FRIEDLANDER, Y.; SAPOZNIKOV, D.; LURIA, M.H. Five minute recordings of heart rate variability for population studies: repeatability and age-sex characteristics. Heart, v. 80, n. 2, p. 156-62, 1998.

STAINSBY, W.N.; BRECHUE, W.F.; O'DROBINAK, D.M. Regulation of muscle lactate production. Med Sci Sports Exercise, v. 23, n. 8, p. 907-911, 1991.

STAMFORD, B.A.; WELTMAN, A.; MOFFATT, R.; SADY, S. Exercise recovery above and bellow anaerobic threshold following maximal work. J Appl Physiol, v. 51, n. 4, p. 840-844. 1981.

TAGARIS, G.A.; RICHTER, W.; KIM, S.G.; GEORGOPOULOS, A.P. Box-Jenkins intervention analysis of functional magnetic resonance imaging data. Neuroscience Research, v. 27, p. 289-294, 1997.

TASK FORCE - Heart Rate Variability - Standards of Measurement, Physiological Interpretation and Clinical Use. Circulation, v. 93, n. 5, p. 1043-1065, 1996.

TEGTBUR, U.; BUSSE, M.W.; BRAUMANN, K.M. Estimation of an individual equilibrium between lactate production and catabolism during exercise. Med Sci Sports Exercise, v. 25, n. 5, p. 620-627. 1993.

TULPPO, M.P.; MAKIKALLIO, T.H.; SEPPÄNEM, T.; LAUKKANEN, R.T.; HUIKURI, H.V. Vagal modulation of heart rate during exercise: effects of age and physical fitness. Am J Physiol, v. 274, p. H424-H429, 1998.

WALSH, R.A. Cardiovascular effects of the aging process. Am J Medicine, v. 82, p. 34-40, 1987. (Suppl. 1B).

WASSERMAN, K.; WHIPP, B. J. Coupling of ventilation in pulmonary gas exchange during nonsteady-steady work in man. J Appl Physiol: Respirat Environ Exercise Physiol. v. 54, p. 587 - 593, 1983

WASSERMAN, K.; WHIPP, B.J. Exercise physiology in health and disease. Am Rev Respir Dis, n. 112, p. 219-249, 1975.

WASSERMAN, K., McILROY, M.B. Detecting the threshold of anaerobic metabolism in cardiac patients during exercise. Am J Cardiol, v. 14, p. 844-852, 1964.

WASSERMAN, K. The anaerobic threshold measurement to evaluate exercise performance. Am Rev Respir Dis, v. 129, p. S35-S40, 1984. (Suppl).

WASSERMAN, K. Overview and future directions. Circulation, v. 81, n. 1, p. 1159-1164, 1990. 
WASSERMAN, K. Critical capillary $\mathrm{PO} 2$ and the role of lactate production in oxyhemoglobin dissociation during exercise. Adv Exp Med Biol, v. 471, p. 321-33, 1999.

WASSERMAN, K; HANSEN, J.E.; SUE, D.; WHIPP, B.J.; CASABURI, R. Principles of exercise testing and interpretation. Lippincott Williams and Wilkings, 3 ed., 1999. 


\section{APÊNDICE 1}

\section{UNIVERSIDADE FEDERAL DE SÄO CARLOS PRÓ - REITORIA DE PÓS - GRADUAÇÃO E PESQUISA COORDENAÇÃO DE PESQUISA COMITÉ DE ÉTICA EM PESQUISA}

O Comitê de Ética em Pesquisa (CEP) da UFSCar, registrado no CONEP/Conselho Nacional de Saúde, pelo ato de 18 de março de 1997, DELIBEROU aprovação sem restrições o projeto com protocolo n 001/01 e titulo: "VALIDAÇÃO DO LIMIAR DE ANAEROBIOSE: APLICAÇÄO DE DIFERENTES MÉTODOS DE ANÁLISE DA VARIABILIDADE DA FREQUÊNCIA CARDIACA" com orientação de Profa. Dra. Ester da Silva.

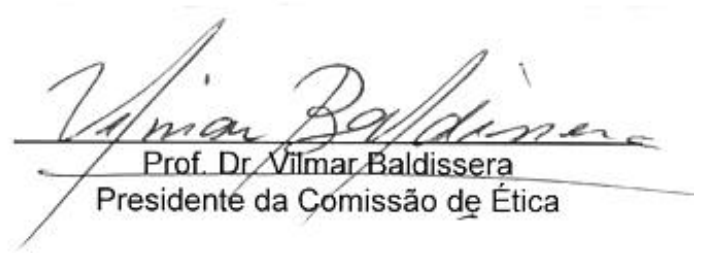


TERMO DE CONSENTIMENTO FORMAL DE PARTICIPAÇÃO NO

ESTUDO: VALIDAÇÃO DO LIMIAR DE ANAEROBIOSE: APLICAÇÃO DE

DIFERENTES MÉTODOS DE ANÁLISE DA VARIABILIDADE DA

FREQUÊNCIA CARDÍACA.

\section{Responsáveis:}

Lilian Cristine de Andrade Teixeira - aluna de Mestrado

Profa. Dra. Ester da Silva - Orientadora

$\mathrm{Eu}$, portador do RG n. ${ }^{\circ}$

residente: Rua n. $^{\mathrm{o}}$

Bairro Cidade de Estado

voluntariamente concordo em participar do projeto de pesquisa proposto pela Fisioterapeuta e pesquisadora Lilian Cristine de Andrade Teixeira, que será realizado no Laboratório de Fisioterapia Cardiovascular do Departamento de Fisioterapia da UFSCar.

A pesquisa tem finalidade observar a modulação das atividades simpática e parassimpática do coração, através da variabilidade da frequiência cardíaca (VFC), bem como observar a ocorrência do limiar de anaerobiose durante exercício físico dinâmico.

Antes do início do teste em questão, serei submetido a uma avaliação constando de anamnese, exame físico e postural e eletrocardiograma (ECG) de repouso deitado e sentado com verificação da FC e da pressão arterial, e exames laboratoriais, com o objetivo de detectar possíveis alterações cardiovasculares, musculares ou articulares que contra-indique minha participação na pesquisa. 
Serei submetido a dois testes de esforço (em bicicleta de frenagem eletromagnética). Estes testes, chamados teste de esforço físico descontínuo, possuem o acréscimo de potência de esforço físico proporcional à potência máxima atingida no esforço contínuo. Cada nível de potência será mantida durante 8 minutos, onde a freqüência cardíaca será registrada 1 minuto antes, 6 minutos durante, e 1 minuto após o esforço. A nova potência será imposta quando os valores da freqüência cardíaca voltarem ao valor de repouso.

O teste de exercício físico dinâmico descontínuo (TEFDD) terá acréscimo de potências progressivas de 10 em $10 \mathrm{~W}$ com duração de 8 minutos em cada nível de esforço físico. O primeiro nível de esforço será realizado na potência de 25 W. Entre uma potência e outra será interposto um período variável de repouso para que os valores de frequiência cardíaca $(\mathrm{FC})$ retornem aos valores basais. Será verificada a potência onde haverá a inclinação da resposta da FC ao esforço físico, refletindo o limiar de anaerobiose. Quando ocorrer a inclinação desta variável, a potência de esforço seguinte será reduzida em $5 \mathrm{~W}$.

Antes de iniciar os testes, serei instruído sobre os sinais e sintomas que devem me alertar a parar a seqüência do teste; ainda serei observado por uma equipe treinada que estará alerta a qualquer alteração que possa sugerir a interrupção do exercício exigido.

Os benefícios que terei com tais procedimentos incluem a verificação de possíveis alterações eletrocardiográficas associadas com a análise dos exames físicos e postural, observando assim, minha situação física. Os testes me possibilitarão reconhecer meus limites fisiológicos durante o exercício físico dinâmico, servindo 
também como parâmetro para treinamento físico que evitem sobrecarga cardiorespiratória, muscular e articular.

As informações obtidas durante as avaliações e os exames laboratoriais serão mantidos em sigilo e não poderão ser consultados por pessoas leigas sem minha expressa autorização por escrito. As informações assim obtidas, no entanto, poderão ser usadas para fins estatísticos ou científicos, sempre resguardando minha privacidade.

Eu li e entendi as informações precedentes. Além disso, todas as dúvidas que me ocorreram já foram sanadas completamente.

Comprometo-me, por meio deste, seguir com o programa até sua finalização, visando reconhecer os meus limites orgânicos, além de me desempenhar para a continuidade do estudo proposto, salvo algum problema que possa surgir que me impossibilite de participar.

São Carlos, de de 2001.

Assinatura do voluntário

Responsáveis:

Profa. Dra. Ester da Silva

Orientadora
Lilian Cristine de Andrade Teixeira

Orientanda 


\section{APÊNDICE 2}

Tabela I. Idade, características antropométricas (peso, altura) e índice de massa corporal (IMC) em Kg/ m${ }^{2}$ observados nos voluntários estudados $(\mathrm{N}=12)$.

\begin{tabular}{|c|c|c|c|c|}
\hline \multicolumn{4}{|c|}{ Voluntários Idade (anos)Peso (kg)Altura (cm) } & $\begin{array}{c}\text { Indice de Massa } \\
\text { Corporal } \\
\left(\mathrm{kg} / \mathrm{m}^{2}\right)\end{array}$ \\
\hline$\overline{\mathrm{ACC}}$ & 43 & 73,0 & 1,71 & 24,96 \\
\hline ADS & 40 & 85,7 & 1,78 & 27,05 \\
\hline $\mathrm{BS}$ & 48 & 69,5 & 1,61 & 26,81 \\
\hline CAC & 41 & 79,0 & 1,77 & 25,22 \\
\hline FMM & 40 & 72,0 & 1,67 & 25,81 \\
\hline $\mathrm{HP}$ & 48 & 70,0 & 1,79 & 21,84 \\
\hline JAC & 41 & 83,0 & 1,76 & 26,79 \\
\hline JRM & 50 & 84,0 & 1,79 & 26,21 \\
\hline MABC & 43 & 67,0 & 1,64 & 20,91 \\
\hline MAF & 40 & 81,0 & 1,73 & 27,06 \\
\hline MR & 43 & 88,0 & 1,73 & 29,40 \\
\hline $\mathrm{VC}$ & 41 & 70,0 & 1,73 & 23,38 \\
\hline Média & 43,16 & 76,80 & 1,72 & 25,45 \\
\hline $\mathrm{DP}$ & 3,53 & 7,36 & 0,06 & 2,39 \\
\hline Mínimo & 40,00 & 67,00 & 1,61 & 20,91 \\
\hline $1^{\circ}$ Quartil & 40,50 & 70,00 & 1,69 & 24,17 \\
\hline Mediana & 42,00 & 76,00 & 1,73 & 26,01 \\
\hline $3^{\circ}$ Quartil & 45,50 & 83,50 & 1,77 & 26,93 \\
\hline Máximo & 50,00 & 88,00 & 1,79 & 29,40 \\
\hline
\end{tabular}

$\mathrm{DP}=$ desvio padrão 
Tabela II: Dados de pressão arterial sistólica (PAS) e diastólica (PAD) em milímetros de mercúrio ( $\mathrm{mmHg}$ ), de frequiência cardíaca (FC) em batimentos por minuto (bpm), em repouso, tipo de atividade física e horas semanais realizadas pelos voluntários $(\mathrm{N}=12)$.

\begin{tabular}{|c|c|c|c|c|c|}
\hline Voluntários & $\begin{array}{c}\text { Atividade } \\
\text { Física }\end{array}$ & $\begin{array}{c}\text { Duração } \\
\text { (horas/semana }\end{array}$ & $\begin{array}{c}P A S \\
(m m H g)\end{array}$ & $\begin{array}{c}P A D \\
(m m H g)\end{array}$ & $\begin{array}{c}F C \\
(b p m)\end{array}$ \\
\hline$\overline{\mathrm{ACC}}$ & corrida & 10 & 120 & 60 & 66 \\
\hline ADS & Caminhada & 2 & 110 & 70 & 60 \\
\hline BS & Caminhada. e corrida & 3 & 106 & 80 & 60 \\
\hline CAC & caminhada & 10 & 115 & 85 & 66 \\
\hline FMM & Caminhada. e bicicleta & 2 & 110 & 60 & 75 \\
\hline $\mathrm{HP}$ & Caminhada. e corrida & 9 & 110 & 70 & 64 \\
\hline JAC & Caminhada & 10 & 120 & 90 & 60 \\
\hline JRM & Corrida & 3 & 140 & 80 & 65 \\
\hline MABC & Caminhada, futsal & 5 & 120 & 60 & 64 \\
\hline MAF & Corrida & 2 & 110 & 80 & 66 \\
\hline MR & caminhada & 2 & 120 & 80 & 66 \\
\hline $\mathrm{VC}$ & $\begin{array}{c}\text { Ginástica aeróbia e } \\
\text { karatê. }\end{array}$ & 4 & 110 & 70 & 51 \\
\hline Média & & 5,16 & 115,91 & 73,75 & 63,58 \\
\hline $\mathrm{DP}$ & & 3,51 & 9,14 & 10,25 & 5,66 \\
\hline Mínimo & & 2,00 & 106,00 & 60,00 & 51,00 \\
\hline $1^{\circ}$ Quartil & & 2,00 & 110,00 & 65,00 & 51,00 \\
\hline Mediana & & 3,50 & 112,50 & 75,00 & 64,50 \\
\hline $3^{\circ}$ Quartil & & 9,50 & 120,00 & 80,00 & 75,00 \\
\hline Máximo & & 10,00 & 140,00 & 90,00 & 75,00 \\
\hline
\end{tabular}

$\mathrm{DP}=$ desvio padrão 
Tabela III: Dados de pressão arterial sistólica (PAS) e diastólica (PAD) em milímetros de mercúrio $(\mathrm{mmHg})$, de frequiência cardíaca (FC) em batimentos por minuto (bpm) e potência pico durante TEFDC-D, realizados pelos voluntários $(\mathrm{N}=12)$.

\begin{tabular}{|c|c|c|c|c|}
\hline Voluntários & $\begin{array}{l}\text { PAS pico } \\
(\mathrm{mmHg})\end{array}$ & $\begin{array}{c}\text { PAD pico } \\
(\mathrm{mmHg})\end{array}$ & $\begin{array}{c}\text { FC pico } \\
(\text { bpm })\end{array}$ & $\begin{array}{l}\text { Potência } \\
\operatorname{pico}(W)\end{array}$ \\
\hline $\mathrm{ACC}$ & 210 & 80 & 175 & 200 \\
\hline ADS & 190 & 95 & 188 & 200 \\
\hline $\mathrm{BS}$ & 190 & 85 & 176 & 175 \\
\hline $\mathrm{CAC}$ & 210 & 100 & 190 & 200 \\
\hline FMM & 190 & 90 & 180 & 175 \\
\hline HP & 190 & 90 & 145 & 175 \\
\hline JAC & 240 & 100 & 180 & 200 \\
\hline JRM & 210 & 100 & 190 & 200 \\
\hline MABC & 210 & 80 & 170 & 200 \\
\hline MAF & 180 & 95 & 190 & 175 \\
\hline MR & 200 & 95 & 183 & 175 \\
\hline $\mathrm{VC}$ & 210 & 90 & 205 & 200 \\
\hline Média & 202,50 & 91,66 & 181 & 188,63 \\
\hline $\mathrm{DP}$ & 16,025 & 7,17 & 14,62 & 13,05 \\
\hline Mínimo & 180 & 80 & 145 & 175 \\
\hline $1^{\mathrm{o}}$ Quartil & 190 & 87,5 & 175,5 & 179,87 \\
\hline Mediana & 205 & 92,50 & 181,5 & 200 \\
\hline $3^{\circ}$ Quartil & 210 & 97,5 & 190 & 197,41 \\
\hline Máximo & 240 & 100 & 205 & 200 \\
\hline
\end{tabular}

$\mathrm{DP}=$ desvio padrão 
Tabela IV: Dados da umidade relativa do ar (\%) e da temperatura em graus Celsius $\left({ }^{\circ} \mathrm{C}\right)$ da sala de experimento mantidas nos dias da realização dos TEFDD$\mathrm{D}(\mathrm{N}=12)$.

\begin{tabular}{|c|c|c|}
\hline \multirow{2}{*}{ Voluntários } & \multicolumn{2}{|c|}{ Umidade Relativa do Ar Temperatura } \\
\hline & $(\%)$ & $\left({ }^{\circ} C\right)$ \\
\hline$\overline{\mathrm{ACC}}$ & 55 & 23 \\
\hline ADS & 60 & 23 \\
\hline $\mathrm{BS}$ & 59 & 23 \\
\hline CAC & 75 & 23 \\
\hline FMM & 59 & 23 \\
\hline $\mathrm{HP}$ & 60 & 23 \\
\hline JAC & 60 & 23 \\
\hline JRM & 58 & 21 \\
\hline MABC & 65 & 21 \\
\hline MAF & 54 & 23 \\
\hline MR & 68 & 23 \\
\hline $\mathrm{VC}$ & 60 & 24 \\
\hline Média & 61,00 & 22,75 \\
\hline DP & 5,77 & 0,86 \\
\hline Mínimo & 54,00 & 21,00 \\
\hline $1^{\circ}$ Quartil & 58,50 & 23,00 \\
\hline Mediana & 60,00 & 23,00 \\
\hline $3^{\circ}$ Quartil & 62,50 & 23,00 \\
\hline Máximo & 75,00 & 24,00 \\
\hline
\end{tabular}

$\mathrm{DP}=$ desvio padrão 
Tabela V: Valores do índice RMSSD dos intervalos R-R em milissegundos (ms) calculados no período de 15 minutos nas condições de repouso supino e sentada dos voluntários $(\mathrm{N}=12)$.

\begin{tabular}{|c|c|c|}
\hline Voluntários & $\begin{array}{c}\text { SUPINO } \\
R M S S D(m s)\end{array}$ & $\begin{array}{c}\text { SENTADO } \\
R M S S D(m s)\end{array}$ \\
\hline$\overline{\mathrm{ACC}}$ & 26,57 & 83,21 \\
\hline ADS & 25,41 & 21,00 \\
\hline BS & 39,47 & 46,63 \\
\hline $\mathrm{CAC}$ & 27,18 & 28,78 \\
\hline FMM & 32,93 & 45,40 \\
\hline $\mathrm{HP}$ & 41,04 & 31,73 \\
\hline JAC & 46,51 & 82,04 \\
\hline JRM & 15,41 & 16,91 \\
\hline MABC & 15,41 & 16,92 \\
\hline MAF & 15,99 & 14,37 \\
\hline MR & 86,72 & 74,51 \\
\hline $\mathrm{VC}$ & 20,87 & 24,02 \\
\hline Média & 32,79 & 40,46 \\
\hline $\mathrm{DP}$ & 19,91 & 25,98 \\
\hline Mínimo & 15,40 & 14,37 \\
\hline $1^{\circ}$ Quartil & 18,43 & 18,96 \\
\hline Mediana & 26,87 & 30,25 \\
\hline $3^{\circ}$ Quartil & 40,25 & 60,57 \\
\hline Máximo & 86,72 & 83,21 \\
\hline
\end{tabular}

$\mathrm{DP}=$ desvio padrão 
Tabela VII. Valores dos índices de RMSSD dos intervalos R-R em milissegundos (ms) calculados para o período de $1^{\circ}$ ao $4^{\circ}$ minuto, do teste de esforço físico dinâmico em degraus descontínuos para as potências de $25 \mathrm{~W}, 35 \mathrm{~W}$, $45 \mathrm{~W}, 55 \mathrm{~W}$ e $65 \mathrm{~W}(\mathrm{~N}=12)$.

\begin{tabular}{cccccc}
\hline \multicolumn{5}{c}{$R M S S D(m s)$} \\
\hline Voluntário & $25 W$ & $35 W$ & $45 W$ & $55 W$ & $65 W$ \\
\hline ACC & 16,91 & 12,98 & 11,03 & 7,15 & 7,26 \\
ADS & 15,41 & 13,49 & 11,55 & 9,88 & 7,72 \\
BS & 17,10 & 18,65 & 16,91 & 15,00 & 10,96 \\
CAC & 29,77 & 20,05 & 19,63 & 10,95 & 12,26 \\
FMM & 9,99 & 6,97 & 6,85 & 5,34 & 5,55 \\
HP & 26,93 & 29,42 & 24,62 & 17,13 & 12,89 \\
JAC & 20,90 & 11,78 & 10,51 & 10,16 & 8,92 \\
JRM & 28,55 & 26,70 & 20,60 & 17,58 & 12,04 \\
MABC & 29,77 & 20,05 & 19,63 & 10,90 & 12,30 \\
MAF & 36,78 & 37,41 & 23,56 & 23,68 & 19,97 \\
MR & 44,97 & 11,00 & 8,02 & 5,58 & 3,42 \\
VC & 13,79 & 11,45 & 13,17 & 10,38 & 8,27 \\
\hline Média & 24,23 & 18,33 & 15,50 & 11,97 & 10,13 \\
DP & 10,35 & 8,98 & 6,08 & 5,43 & 4,29 \\
Mediana & 23,91 & 16,07 & 15,04 & 10,64 & 9,93 \\
$1^{\circ}$ Quartil & 16,15 & 11,61 & 10,76 & 8,51 & 7,49 \\
$3^{\circ}$ Quartil & 29,77 & 23,37 & 20,11 & 16,06 & 12,28 \\
Mínimo & 9,99 & 6,96 & 6,85 & 5,34 & 3,42 \\
Máximo & 44,97 & 37,41 & 24,61 & 23,68 & 19,97 \\
\hline W = Watts; DP = desvio & adrão & & &
\end{tabular}

$\mathrm{W}=$ Watts; DP = desvio padrão 
Tabela VIII. Resultados dos ajustes dos modelos autorregressivos integrados médias móveis (ARIMA) e semiparamétrico ao conjunto de dados de frequiência cardíaca em todas as potências realizadas pelos voluntários $(\mathrm{N}=12)$.

\begin{tabular}{|c|c|c|c|c|c|c|}
\hline & \multicolumn{3}{|c|}{ Modelo ARIMA } & \multicolumn{3}{|c|}{ Modelo Semiparamétrico } \\
\hline Voluntário & $P O T(W)$ & $F C($ bpm $)$ & $Q M R$ & $P O T(W)$ & $F C($ bpm $)$ & Inclinação (á) \\
\hline $\mathrm{ACC}$ & 55 & 95 & 1,99 & 55 & 93 & $0,0090^{*}$ \\
\hline ADS & 55 & 115 & 2,85 & 65 & 99 & $0,0120 *$ \\
\hline $\mathrm{BS}$ & 60 & 90 & 1,04 & 60 & 91 & $0,0140 *$ \\
\hline CAC & 55 & 94 & 4,52 & 50 & 87 & $0,0008 *$ \\
\hline FMM & 45 & 97 & 1,41 & 45 & 101 & $0,0080 *$ \\
\hline $\mathrm{HP}$ & 65 & 92 & 2,40 & 65 & 92 & $0,0190 *$ \\
\hline JAC & 75 & 97 & 4,65 & 65 & 95 & $0,0150 *$ \\
\hline JRM & 85 & 101 & 3,29 & 85 & 101 & $0,0110 *$ \\
\hline MABC & 75 & 85 & 1,92 & 50 & 90 & $0,0070 *$ \\
\hline MAF & 45 & 103 & 7,56 & 45 & 103 & $0,0039 *$ \\
\hline MR & 60 & 102 & 1,34 & 45 & 105 & $0,0230 *$ \\
\hline $\mathrm{VC}$ & 85 & 125 & 4,24 & 85 & 117 & $0,0060 *$ \\
\hline Média & 63,33 & 100,00 & 3,10 & 59,83 & 98,00 & 0,1042 \\
\hline $\mathrm{DP}$ & 13,87 & 11,00 & 1,88 & 14,21 & 8,00 & 0,0067 \\
\hline Mediana & 60,00 & 97,00 & 2,62 & 57,50 & 97,00 & 0,1000 \\
\hline $1^{\circ}$ Quartil & 55,00 & 93,00 & 1,66 & 47,50 & 91,00 & 0,0065 \\
\hline $3^{\circ}$ Quartil & 75,00 & 102,00 & 4,38 & 65,00 & 102,00 & 0,0145 \\
\hline Mínimo & 45,00 & 85,00 & 1,04 & 45,00 & 87,00 & 0,0003 \\
\hline Máximo & 85,00 & 125,00 & 7,56 & 85,00 & 117,00 & 0,0230 \\
\hline
\end{tabular}

$\overline{\text { POT }=\text { Potência em Watts }(\mathrm{W}) ; \mathrm{FC}=\text { freqüência cardíaca em bpm (batimentos por }}$ minuto); SP = semiparamétrico; Inclinação = coeficiente angular da reta, dada pelo ajuste do modelo semiparamétrico; $\mathrm{QMR}=$ quadrado médio dos resíduos; $\mathrm{DP}=$ desvio padrão. * Nível de significância $\mathrm{p}<0,05$. 
Tabela IX. Valor do índice RMSSD dos intervalos R-R calculados para o período do $1^{\circ}$ ao $4^{\circ}$ minuto, do teste de esforço físico dinâmico em degraus descontínuos, nas potências em que ocorreu o limiar de anaerobiose determinado pelas metodologias ARIMA (ajustes dos modelos autorregressivos integrados médias móveis) e SP (semiparamétrico) $(\mathrm{N}=12)$.

\begin{tabular}{|c|c|c|c|c|}
\hline \multirow[b]{2}{*}{ Voluntário } & \multicolumn{2}{|c|}{ Modelo ARIMA } & \multicolumn{2}{|c|}{ Modelo Semiparamétrico } \\
\hline & $P O T(W)$ & $R M S S D(m s)$ & $P O T(W)$ & $\overline{R M S S D}(\mathrm{~ms})$ \\
\hline $\mathrm{ACC}$ & 55 & 7,15 & 55 & 7,15 \\
\hline ADS & 55 & 9,88 & 65 & 7,72 \\
\hline BS & 60 & 12,54 & 60 & 12,54 \\
\hline CAC & 55 & 10,95 & 50 & 22,65 \\
\hline FMM & 45 & 6,85 & 45 & 6,85 \\
\hline $\mathrm{HP}$ & 65 & 12,89 & 65 & 12,89 \\
\hline JAC & 75 & 10,02 & 65 & 8,92 \\
\hline JRM & 85 & 10,59 & 85 & 10,59 \\
\hline MABC & 75 & 7,98 & 50 & 9,28 \\
\hline MAF & 45 & 23,56 & 45 & 23,56 \\
\hline MR & 60 & 4,35 & 45 & 8,02 \\
\hline $\mathrm{VC}$ & 85 & 5,94 & 85 & 5,94 \\
\hline Média & 63,33 & 10,22 & 59,83 & 11,34 \\
\hline DP & 13,87 & 4,95 & 14,21 & 5,89 \\
\hline Mediana & 60,00 & 9,95 & 57,50 & 9,10 \\
\hline $1^{\circ}$ Quartil & 55,00 & 7,00 & 47,50 & 7,43 \\
\hline $3^{\circ}$ Quartil & 75,00 & 11,74 & 65,00 & 12,71 \\
\hline Mínimo & 45,00 & 4,35 & 45,00 & 5,94 \\
\hline Máximo & 85,00 & 23,56 & 85,00 & 23,56 \\
\hline
\end{tabular}

POT = Potência em Watts (W); ARIMA = ajustes dos modelos autorregressivos integrados médias móveis; $\mathrm{SP}=$ semiparamétrico; $\mathrm{DP}=$ desvio padrão; milissegundos (ms). 